\title{
The Development of Social Comparisons and Sharing Behavior Across 12 Countries
}

\author{
Anya Samek ${ }^{1}$, Jason M. Cowell ${ }^{2,16}$, Alexander W. Cappelen ${ }^{3}$, Yawei Cheng ${ }^{4}$, Carlos Contreras- \\ Ibáñez $^{5}$, Natalia Gomez-Sicard ${ }^{6}$, Maria L. Gonzalez-Gadea ${ }^{7}$, David Huepe $^{8}$, Agustin Ibáñez ${ }^{7}$, 8, 9 , \\ ${ }^{17}, 18$ Kang Lee ${ }^{10}$, Susan Malcolm-Smith ${ }^{11}$, Natalia Salas ${ }^{12}$, Bilge Selcuk ${ }^{13}$, Bertil Tungodden ${ }^{3}$, \\ Alina Wong ${ }^{14}$, Xinyue Zhou ${ }^{15}$, and Jean Decety ${ }^{16}$
}

$\mathrm{S}$

1. Department of Economics, The University of Southern California, Los Angeles, USA

2. Department of Psychology, The University of Wisconsin Green Bay, USA

3. Department of Economics, Norwegian School of Economics, Norway

4. Institute of Neuroscience and Brain Research Center, National Yang-Ming University, Taipei, Taiwan

5. Department of Sociology, Universidad Autónoma Metropolitana-Iztapalapa, Mexico

6. Research Division Neurosketch SAA, Bogota, Colombia

7. Institute of Cognitive and Translational Neuroscience (INCYT), INECO Foundation, Favaloro University, Buenos Aires, Argentina

8. Center for Social and Cognitive Neuroscience, School of Psychology, Universidad Adolfo Ibáñez, Santiago, Chile

9. National Scientific and Technical Research Council (CONICET), Argentina

10. Erick Jackman Institute of Child Study, University of Toronto, Canada

11. Department of Psychology, University of Cape Town, South Africa

12. Faculty of Education, Universidad Autónoma de Chile, Chile

13. Department of Psychology, Koc University, Turkey

14. Dirección de Extensión Universitaria, Universidad de La Habana, Cuba

15. School of Management, Zhejiang University, China

16. Department of Psychology, University of Chicago, Chicago, USA

17. Universidad Autónoma del Caribe, Barranquilla, Colombia

18. Australian Research Council Centre of Excellence in Cognition and its Disorders, Sydney, Australia

Acknowledgements: This research was funded by a grant from the John Templeton Foundation through the Science of Philanthropy Initiative. 


\section{Introduction}

Humans are an ultra-social species. A key feature of successful human interaction is prosocial preferences and concern for others' welfare. Research indicates that children are naturally prosocial (Warneken and Tomasello, 2009). For example, toddlers engage in spontaneous helping behaviors (Warneken and Tomasello, 2007), and children as young as age 3 understand principles of fairness, even if they do not always follow them (Blake et al., 2014). A robust literature also suggests that the propensity to engage in prosocial behaviors increases as children grow up (Decety and Svetlova, 2012)). For example, children ages 3-4 are mostly selfish, while children ages 7 and older are more prosocial when sharing resources with others (Bar-Tal et al., 1980; Benenson et al., 2007; Cowell \& Decety, 2015; Fehr et al., 2008; Devanath, 2010).

There is evidence that several nuanced behaviors and preferences related to prosociality emerge during childhood (Warneken and Tomasello, 2007). As children get older, they are more likely to display reciprocity by sharing more when others share (Olson and Spelke, 2008; House et al., 2013; Sebastián-Enesco et al., 2013). They are more likely to display parochialism by sharing more with in-group versus out-group peers (Fehr et al., 2013). Four-year-old children reject disadvantageous inequality, while 8-year-olds reject both advantageous and disadvantageous inequality (Blake and McAuliffe, 2011). Older children are also more prone to strategic thinking and consideration of efficiency when deciding how much to share (Almås et al., 2010; BerebyMeyer and Fiks, 2013). Finally, older children are more susceptible to recipient characteristics when deciding whether to share, and incorporate merit-based considerations (Almås et al., 2010; Kogut et al., 2016; Malti et al., 2016). On the other hand, behaviors such as spite become less frequent as children get older (Fehr et al., 2013). 
Sharing is also prevalent among adults. In a standard dictator game in the laboratory, participants are given an endowment of money and asked to decide how much to share with an anonymous stranger. Meta-analysis of hundreds of dictator game experiments showed that adult subjects share around 30\% of their endowment (Engel, 2011). Evidence of sharing is also observed in the economy. In $2017,42 \%$ of people from developed nations and $24 \%$ of people from developing nations indicated that they had donated to charity that year (Charities Aid Foundation, 2018). In the United States (US), the charitable giving sector makes up more than $2 \%$ of the gross domestic product (GDP) (List, 2011). The fact that people voluntarily pay their taxes and often vote for higher taxes also provides evidence of prosocial behavior among adults (Andreoni et al., 1998).

Socialization is one mechanism through which children may become more prosocial as they grow older. Rushton (1976) reviews early work on this concept, showing that children are susceptible to models, preaching and induction. Observing the sharing behavior of parents may cause children to internalize sharing norms and increase their own sharing in response. In support of this, Blake et al. (2016) showed that children 3-8 years-old in India and the US were influenced to share less when they saw their parent modeling a stingy donation. Children in India (but not the US) were influenced to share more when they saw their parent modeling a generous donation. BenNer et al. (2017) showed that 3-5-year-olds who initially shared less were influenced by a parent modeling a donation to share more. Cappelen et al. (2016) found that the fairness views of 7-8year-old children were affected by exposure to preschool and parenting programs early in life. Socialization may also explain why research finds that children's sharing behavior is influenced by parental background (Bauer et al., 2014) and parenting style (Mesurado et al., 2014). 
Key contributors to socialization beyond parents are peers. Peers have been observed to influence how much children display generosity, both in terms of children wanting to appear fair in front of peers, and children wanting to emulate peers on a host of different social cognitions. For decades, researchers have argued that in many situations, peers become a prominent subject of imitation and anchoring in expectations over middle and late childhood (e.g., Bronfenbrenner, 1979; Hartup and Moore, 1990; Harris, 1998). Historical aspects of this research have focused on the influential role that group and peer relations play on increasingly anti-social conduct in late childhood, as is evidenced by the famous Robbers Cave experiment (Sherif, 1954). Here, children began to engage in increasingly hostile acts towards outgroup members, partially due to a rising identification with the ingroup, and partially based on peer influences. The role of peer influence towards adolescent smoking (e.g., Chassin, Presson, Sherman, Monetllo, and McGrew, 1986), drug and alcohol use (Bauman and Ennett, 1996), risky decision making (e.g., Gardner and Steinberg, 2005) as well as early promiscuity (Dishion,2000) have also been well documented, Some have even argued that adolescence is a period of particular sensitivity to peer influence (Steinberg and Silverberg, 1986), hence the heavy influence on deviant behaviors.

Peer influence in a host of social and social cognitive abilities also appears to take place much earlier than adolescence/preadolescence. In foundational work from Maccoby (1990), children's gender-specific play and behaviors appear as young as three years of age, suggesting at least some level of peer influence in behavior in early childhood. Moreover, some authors have argued that complex models of early problem behaviors include peer influences from early through middle childhood (Keenan \& Shaw, 1997).

Some research has also examined the effects of peers on positive behaviors, particularly in adolescence. For instance, one study showed that peers influence adolescent sharing behavior (van 
Hoorn et al., 2014). There is some evidence for a decline in peer influence during adolescence and through adulthood (Steinberg and Monahan, 2007). However, they are still subject to peer influence. In a series of experiments, adults who called to make a charitable contribution to a public radio station were influenced to give higher or lower amounts when given information about a recent donation (Croson and Shang, 2008; Shang and Croson, 2009).

This influence of peers appears to extend to the prosocial domain as well, yet the mechanism for influence remains unknown: children are directly guided through peer feedback and modeling (from a social learning perspective; e.g., Bandura, 1977) and/or through a drive to appear fair in front of others (e.g., Shaw et al., 2014). The latter author has provided evidence that as children grow up, they develop the desire to appear fair to peers, which results in greater generosity. That is, the generosity that children display results from both a desire to be fair, and a desire to show others that they are fair (Shaw et al., 2014). Peer modeling can also shape sharing behavior, and this effect may increase with age during childhood. In an influential study, Berndt (1979) asked children to respond to hypothetical situations in which peers or parents displayed prosocial, antisocial or neutral behaviors. Berndt (1979) found that peer influence was higher and parent influence was lower among older children. More recently, Santamaría-García and colleagues (2018) found that children above 9 years old shared more pieces of candy depending on the beliefs about others. Overall, beliefs about the functioning of the social world may guide social behavior in children. One study conducted a stated preference experiment in which children, adolescents and adults rated their probability of engaging in a prosocial behavior with and without information about the stated preferences of others (Foulkes et al., 2018). Children ages 8-11 (the youngest cohort in the study) were most likely to increase their likelihood of engaging in the prosocial behavior when they were exposed to social influence. 
Additional research on conformity to group opinions, expectations, and standards, also suggests that some level of peer influence can be observed as young as four years of age and may be dependent upon minority or majority ethnic group status (Haun and Tomasello, 2011). Yet, integrating peer influence and observation with smaller changes to behavior appears later in childhood, around 8 years of age (Banerjee, 2002). Thus, several lines of research suggest that the cognitive or social cognitive factors modulating the influence of peers in prosocial behaviors will change as children develop across early and middle childhood, with the possibility that older children will be more susceptible to peer influence.

The development of prosociality may also follow different paths cross-nationally due to differences in cultural norms, parenting styles and potentially even the development of cognitive abilities across countries (e.g., due to differences in schooling structures). Social scientists have commonly relied on the individual-collectivism (I-C) dichotomy to explain differences across countries. Countries with a more individualistic culture prioritize individual goals while countries with a more collectivist culture prioritize group goals (Triandis, 1996; 2001). Therefore, children from collectivist countries (typically Eastern countries) are frequently thought to be more prosocial than children from individualist countries (typically Western countries) (de Guzman, Do \& Kok, 2014). For example, Israeli children living in kibbutz communities that emphasize communal living have been shown to display more prosocial behaviors (Shapira and Madsen, 1969; 1974; Madsen and Shapira, 1977; Eisenberg et al., 1990).

Further empirical evidence for the individual-collectivism dichotomy remains limited, partly because few studies collect data from enough nations or cultures using the same paradigm. Stewart and McBride-Chang (2000) examined sharing behavior of students in Hong Kong, finding that students from Asian cultures shared marginally more than students from Western Caucasian 
cultures. Rao and Stewart (1999) found that Chinese children were more likely to share spontaneously than Indian children. But Yagmurlu and Sanson (2009) found similar prosocial behaviors from native Australian or Turkish preschoolers living in Australia (children of migrant families). Related work has not examined susceptibility to social information by country, but one possibility is that children from collectivist countries - which emphasize group goals - are also more susceptible to peer modeling.

Culture may also influence the age-related trajectory of prosocial behaviors. This is because as children grow up, they have more time to internalize social norms, parent models or their environment. For example, different types of schooling can affect prosocial behaviors and beliefs, either through cognitive or social channels (e.g., see Flook et al., 2015; Cappelen et al., 2016; Khomych, 2018). Supporting this idea, Cowell et al. (2017) found that egalitarianism emerged earlier in children from the United States, Canada and China versus South Africa and Turkey. Another large-scale study included three distributive justice games with children ages 411 in 12 diverse countries (Huppert et al., 2019). The authors found that overall, younger children were more likely to use equality-based strategies while older children were more likely to use equity-based strategies. They also reported that children from the most individualistic cultures shifted to equity-based strategies at younger ages. Again, related work has not explored susceptibility to social information by country and age, but it is possible that collectivist countries encourage children to consider group/peer behaviors at younger ages as compared to individualist countries who focus children more on individual goals. 


\section{This Study}

The goal of the current study was to evaluate the development of social comparisons and sharing behaviors with a large sample of children ages 3-12 years old. In the experiment, children participated in a dictator game in which they had the opportunity to share up to 10 of their stickers with an anonymous child. Then, children were randomized to one of two treatments. In the "shared a little" treatment, children were told that another child from their school had shared 1 sticker, while in the "shared a lot" treatment, children were told that another child from their school had shared 6 stickers in the same game. Finally, children had the opportunity to play the game again by sharing up to 10 new stickers with a different anonymous child.

One innovation of the study is the use of a sample recruited from 12 diverse countries across 5 continents. The countries included Argentina, Canada, Chile, China, Colombia, Cuba, Mexico, Norway, South Africa, Taiwan, Turkey and the United States. This diverse sample allows us to study potential cross-national differences in the development of sharing behavior and the susceptibility to social comparisons. Recruitment of participants from a diverse set of countries is important to evaluate cross-national variation in the development of social preferences. Prior work has been limited in this regard since it has mostly focused on children from so-called WEIRD (Western, Educated, Industrial, Rich, Democratic) populations (Nielsen et al., 2017; Henrich et al., 2010).

Furthermore, the fact the study was conducted in multiple countries is also important in light of recent concerns about a "replication crisis" in the social sciences. A major reason for the replication crisis is the relatively small sample sizes in most studies (Maxwell et al., 2015). The relatively large sample size - including studies in 12 different countries with different cultural backgrounds that allow us to test the robustness of our findings - gives us a great deal of confidence 
in our conclusions. By including developing countries and countries from Asia, Africa and South/Central America, the sample also speaks to the generalizability of our findings to a broader sample and allows us to address the bias in psychological research that arises from a historic focus on WEIRD populations (Nielsen et al., 2017).

Our first prediction was that age would be positively associated with sharing behavior. This follows related work showing a robust positive association of sharing and age (e.g., Fehr et al., 2008). Our second prediction was that age would be positively associated with responsiveness to social information. That is, older children would be more likely to change their sharing behavior in the second dictator game in response to the social information, while younger children would not change their behavior. This follows from related work showing a more nuanced attitude toward sharing as children get older. It also follows from Shaw et al. (2014) who report that children's desire to appear fair increases with age, and from related work on peer influence, which finds that children become more susceptible to modeling with age. Our third prediction was that children from collectivist countries, versus individualist countries, would be more likely to respond to social information, or that we would see responsiveness to social information at a younger age. This follows related work that uses the individual-collectivism dichotomy to evaluate prosociality and cultural attitudes.

\section{Methods}

\subsection{Participants}

Children $(\mathrm{N}=2,331)$ were tested in 12 countries: Argentina, Canada, Chile, China, Colombia, Cuba, Mexico, Norway, South Africa, Taiwan, Turkey and the United States. ${ }^{1}$ Table

\footnotetext{
${ }^{1}$ Children were also initially tested in Jordan. However, the Jordan experiment failed to conduct the randomization properly. Therefore, the Jordan data is excluded from the analysis.
} 
A1 in the appendix provides details about the sample. Children were aged 3-12 years, with an average age of 7.68 years $(\mathrm{SE}=0.06)$ and about an even distribution across each year of age. $51.5 \%$ of the children were female. Appendix Figure A1 provides a histogram of participant age distributions (and Figure A2 provides the same information broken down by country).

The study was conducted in 2015-16. The children were recruited from major cities in each country, chosen because they were convenient and represented a geographical range of urban environments. Each country conducted their own recruitment procedure with the goal of recruiting about 200 participants. Most of the recruitment was conducted through local schools. Appendix Table A2 provides further information about recruitment in each country.

Parents provided consent and children provided assent prior to participating in the study. The study was approved by University of Chicago Institutional Review Board (IRB) and the local IRB in each country. Since the parent survey was voluntary, it is missing in some cases. The main analysis was performed on the full sample. An additional regression analysis was performed

controlling for socioeconomic status and household size information from the parent survey - these data are available for 2,116 children. There are no systematic differences between the full sample and this sub-sample (e.g., in the full sample the average age is $7.68(\mathrm{SE}=0.06)$, in the sub-sample the average age is $7.66(\mathrm{SE}=0.06)$; in the full sample the \% female is 51.5 and in the sub-sample the $\%$ female is 51.5 ). The appendix provides more details about the data exclusions and the missing data.

\subsection{Procedure}

Research teams from each country attended a retreat in person and learned the protocol for the study, which was prepared by the Child Neurosuite at the University of Chicago. The study 
included the social comparisons task in the present study, as well as several other behavioral economics tasks. The only results that have so far been published from this data set are from the distributed justice games (Huppert et al. (2019). None of the tasks conducted prior to the games we report on here were incentivized or involved making dictator-game like decisions. Rather, they were hypothetical questions about different scenarios. Importantly, there is no reason to believe that these tasks would interact with the treatment effect, which is what we ultimately measure in this paper.

Children participated in the experiment one-on-one with a trained experimenter, who read the instructions out loud (see appendix). Parents also completed a short written survey about their child and household. The study materials were translated into the local language by nativelanguage speakers for each of the 12 countries. The study materials were then translated back into English to ensure accuracy.

In the experiment, we first collected baseline sharing behavior using a dictator game. This measure was used as a control in our analysis. We next provided children with information about the sharing behavior of another anonymous child. Finally, children played a second dictator game. Between the first dictator game and receiving information about sharing behavior of another child, children also participated in a short survey in which they were asked to evaluate several unrelated scenarios.

\section{Measures}

\subsection{Dictator Game Experiments}

For the first dictator game, children picked 10 of their favorite stickers from a pile of 30 stickers and were told that the stickers belonged to them. The selection of stickers for children was 
originally made by the research team in each country to account for potential cultural differences in the salience of rewards. Children then chose how many of their stickers to share with an anonymous other child (gender matched). They were told that the other child would come in that day but would not get stickers. Children were given two envelopes, one labeled with the child's name and another labeled with "other boy/girl." They were asked to confirm their understanding by repeating which envelope belonged to them and which envelope belonged to the other girl or boy. To give the child privacy, the experimenter then closed his or her eyes while the child put stickers he/she wanted to keep in his/her envelope and the stickers he/she wanted to give away in the envelope for the other child. After children left, unbeknownst to them, we opened the envelope and counted how many stickers they shared with the other child.

Before the second dictator game, children were randomized to one of two treatments. Children were told that another girl or boy (gender matched) from their school had played the same sticker game. In the "shared a little" treatment, they were told that the other girl or boy gave 1 sticker to another (gender matched) child and kept 9 for themselves. In the "shared a lot" treatment, they were told that the other girl or boy gave 6 stickers to another child and kept 4 for themselves.

The second dictator game proceeded like the first. Children chose 10 new stickers to play with from a new pile of 30 stickers. Then, children chose how many of their stickers to share with another different boy or girl (also gender matched).

In keeping with common practice in psychology, in most countries we did not actually distribute stickers to other anonymous children. However, in Norway, at the end of the study, the stickers were actually distributed to other non-participating children based on the allocations selected by the participating children. 


\subsection{Parent Survey}

Parents were asked to complete a short survey. The survey included demographic questions about the child, such as age, gender, and race. The survey also included information about family size and number of siblings. We used these variables as controls in the analysis. The survey also included a multiple-choice question about the mother's highest level of educational attainment or years of schooling, with the following options: graduate or professional degree, bachelor's degree, 13-16 years, 9-12 years, 6-8 years, and 0-5 years. The measure of mother's educational attainment was used as a proxy for socioeconomic status following related work (e.g., Winkleby et al., 1992).

\subsection{Country Categorization}

Following Huppert et al. (2019), we categorized countries as individualist-collectivist using the Hofstede score (Hofstede et al., 2010). This score captures the level of individualism or collectivism within a country, where 100 indicates countries with the highest level of individualism and 0 indicates countries with the highest level of collectivism. The Hofstede scores, organized from most individualist to most collectivist, were as follows: United States (91), Canada (80), Norway (69), South Africa (65), Argentina (46), Turkey (37), Mexico (30), Chile (23), China (20), Taiwan (17), Colombia (13) and Cuba (12).

\subsection{Analysis}

The main variable of interest was the number of stickers shared (out of 10) by treatment condition ("shared a lot" or "shared a little") in the second dictator game. Our primary analysis consisted of an ordinary least squares (OLS) regression with number of stickers shared as the outcome variable of interest, a dummy for treatment (equal to 1 in the "shared a lot" treatment and 
0 in the "shared a little" treatment). The child age at the time of the study was entered linearly into the regression. Alternative specifications included controls for sharing behavior in the first dictator game, child gender, child race, mother's educational attainment, and number of children in the household. Additional regression models were used to examine the interactions of treatment with age. The Hosftede score was added into the models to evaluate whether country-level differences in individualism-collectivism influence sharing behavior or treatment effects.

\section{Results}

\subsection{Data}

We expected to be balanced on characteristics by treatment, since treatment assignment was random. The characteristics of children across the two treatments were similar. When conducting t-tests separately for each characteristic, such as age, gender, number of children in household and mother's educational attainment, there were no statistically significant differences, except for a slight difference by age, which is statistically significant - the "share a lot" treatment children were on average 4 months older $(t(2,329)=2.51, p=0.01, d=0.10)$. The groups did not differ by baseline sharing rate: the baseline sharing in the "share a little" treatment was 3.82 (s.e. $=0.07$, stdev $=2.42$ ) and the baseline sharing in the "share a lot" treatment was 3.87 (s.e. $=0.07$, stdev=2.36) $(\mathrm{t}(2,329)=0.38, \mathrm{p}=0.70, \mathrm{~d}=0.02)$. Further, the groups did not differ in terms of distributions of sharing behavior (Kolmogorov-Smirnov test of distributions $\mathrm{p}$-value $=0.60$ ). Hence, in most of the analysis we controlled for age. Appendix Table A3 shows the balance of demographic variables with respect to treatment assignment, including p-values for t-tests comparing the treatments. 


\subsection{Dictator Game Behavior}

We initially summarized behavior in the first dictator game. Figure 1 provides a histogram of dictator game giving in the first game (Figure A4 in the appendix provides the same histograms broken down by country). As expected, most children shared half or less than half of their stickers (stickers shared less than or equal to 5). The modal number of stickers shared is at the "fair" $5 / 5$ split. A non-negligible number of children chose not to share any stickers. This observation mimics related work on sharing in this age group.

\section{Figure 1: Histogram of Baseline Sharing Behavior}

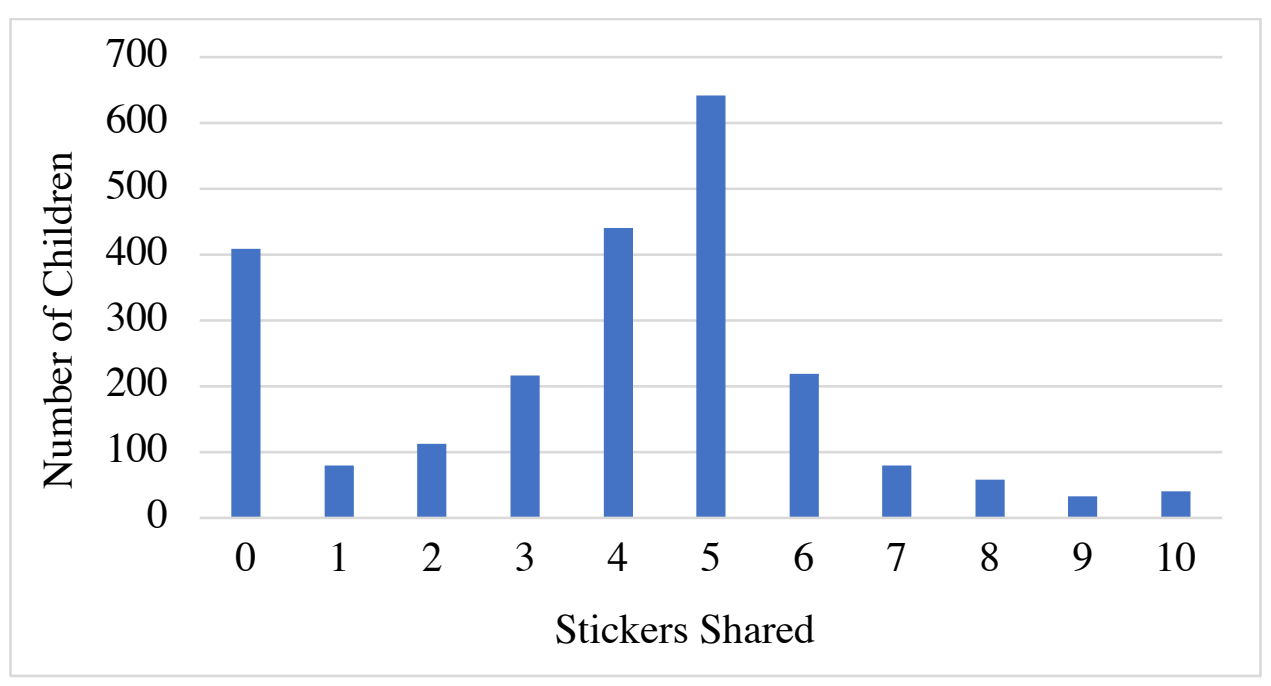

Note: This figure shows a histogram of sharing behavior in the first dictator game, out of 10 stickers.

Figure 2 shows the trajectory of sharing behavior with age, including standard error bars (Figure A5 provides line graphs broken down by country). Like related work, we observe that sharing increases with age. 3-year-old children share approximately 3 stickers, 8 -year-old children shared approximately 4 stickers, and 11-12-year-old children share approximately 5 stickers. There were also interesting distributional shifts in sharing by age reported in Appendix Figure A3. Notably, the modal level of sharing of 3-4-year-olds was 0 , and 3-year-olds did not exhibit a spike 
in sharing at 5. On the other hand, there was a stronger "fairness norm" in terms of sharing 5 for children aged 8 and up. A Spearman correlation of age and mean sharing found a correlation coefficient of 0.34 ( $p$-value $<0.01)$ and a correlation of age and whether or not children shared equally found a correlation coefficient of 0.17 ( $p$-value $<0.01$ ).

Figure 2: Mean Stickers Shared, by Age

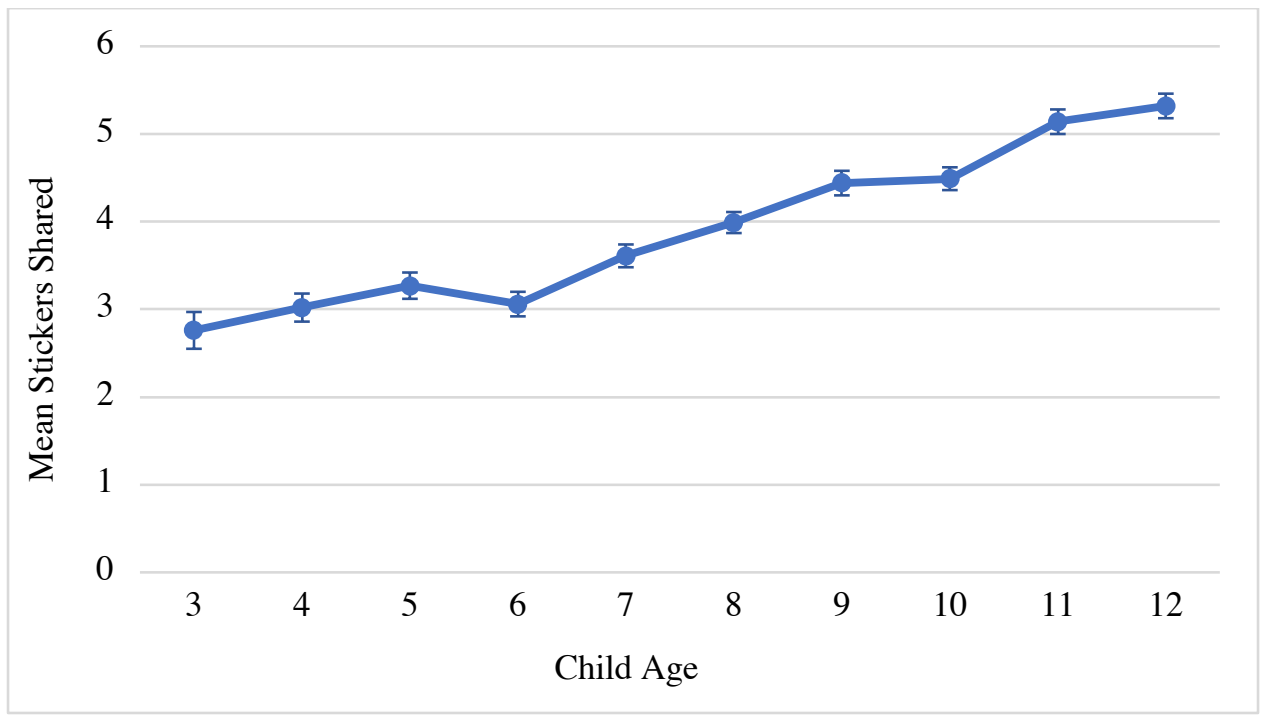

Note: This line chart shows the mean stickers shared, by age. Bars depict standard errors.

\subsection{Treatment Effects}

We turned to the evaluation of the impact of the "shared a lot" and "shared a little" treatments on sharing. Recall that there were no significant differences between these groups in baseline sharing behavior. We found statistically significant differences in sharing across treatments, with children in the "shared a lot" condition sharing about half a sticker more than in the "shared a little" condition. Children shared $3.92(\mathrm{SD}=2.57)$ stickers in the "shared a little" condition and $4.40(\mathrm{SD}=2.63)$ stickers in the "shared a lot" condition $(\mathrm{t}(2,329)=4.43, p<0.001$, $\mathrm{d}=0.18$ ). Given this large sample size, we had a power of 0.99 to detect this effect size. Figure 3 provides histograms of sharing, with the left panel displaying the "shared a little" condition and 
the right panel displaying the "shared a lot" condition (Figures A6 and A7 show histograms for each treatment broken down by country).

Figure 3: Histograms of Sharing, by Treatment
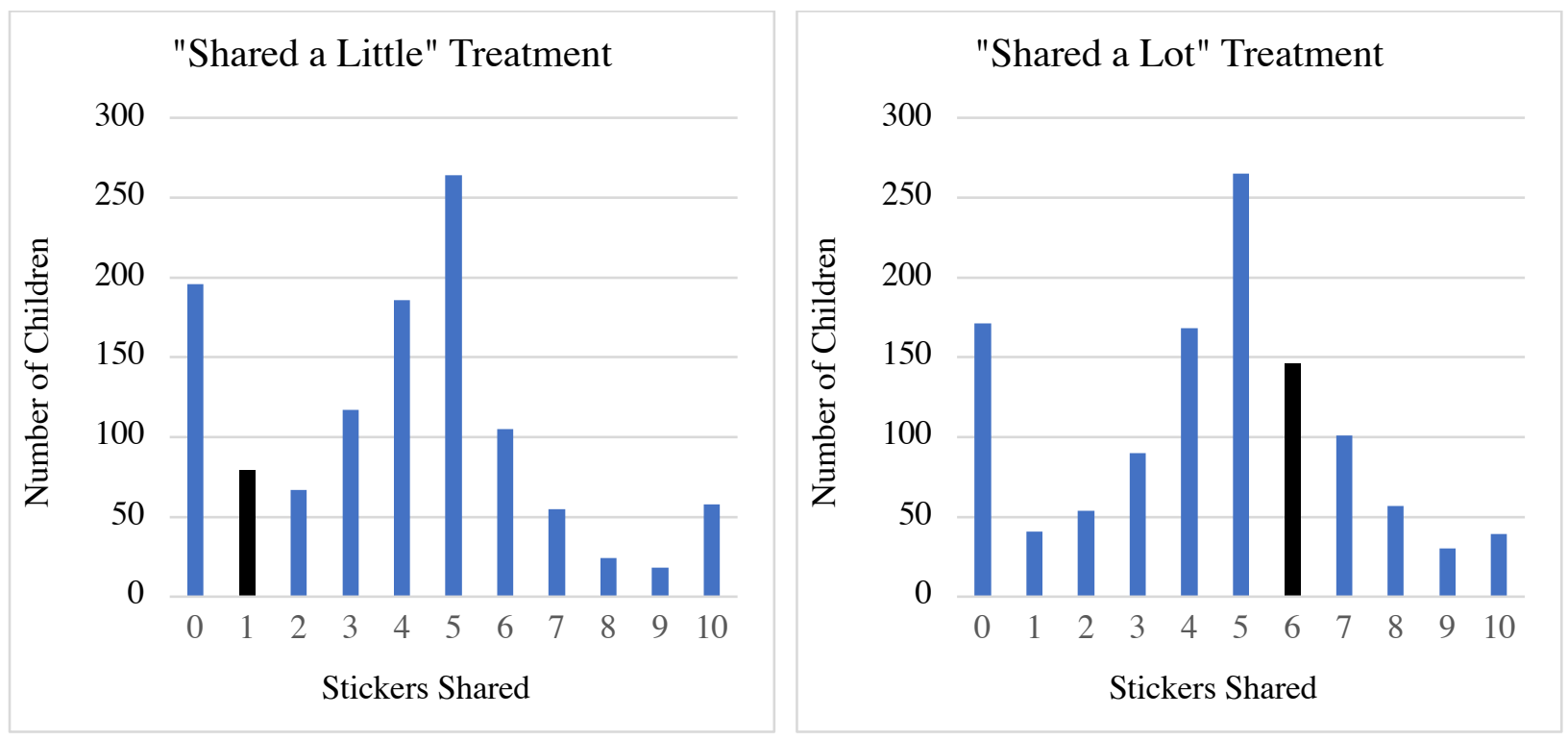

Note: This figure shows histograms of stickers shared, with the "shared a little" treatment on the left and the "shared a lot" treatment on the right. The sharing amount modeled in the experiment is depicted in a darker color.

The sharing amount modeled in the experiment ( 1 in the "shared a little" condition and 6 in the "shared a lot" condition is highlighted in a darker color for reference. If the treatment effect were due to anchoring (i.e., selecting the same number as the model), we would expect larger sharing rates at these bars. We see some evidence of anchoring. While only $3.4 \%$ (80 of 2,331$)$ of children chose to share 1 sticker in the baseline dictator game, $6.8 \%(79$ of 1,169$)$ did so in the second dictator game in the "shared a little" treatment. This compared to only $3.5 \%(41$ of 1,162$)$ in the "shared a lot" treatment. Similarly, while only $9.4 \%$ (219 of 2,331$)$ of children chose to share 6 stickers in the baseline dictator game, $12.6 \%$ (146 of 1,162) did so in the second dictator game in the "shared a lot" treatment. This compared to only $9.0 \%(105$ of 1,169$)$ in the "shared a little" treatment. Appendix Table A4 provides additional analysis of anchoring by regressing an 
indicator variable of whether or not a child shared 1 sticker or 6 stickers on the treatment dummies, baseline sharing and demographic controls. Indeed, we see that the treatment dummy is statistically significant and in the expected direction, suggesting that the treatment "shared a lot" increased likelihood of sharing 6 and decreased likelihood of sharing 1 .

Figure 4 shows the evolution of sharing behavior by treatment with age (Figure A8 shows the same information broken down by country). As in the dictator game, we observed that sharing behavior increased with age. Children in the "shared a lot" condition tended to share more than children in the "shared a little" condition, and that this effect seemed to be concentrated among the children in the middle of our age distribution. We observed that children as young as age 5 seemed to be affected by the "shared a lot" treatment, though the biggest effects seemed to be for children ages 7-9. Relatedly, McAuliffe et al. (2017) tested children aged 4-9 and noted that the older children were more influenced by a generous sharing norm. Note that a formal test of an interaction effect of treatment with age did not yield a statistically significant coefficient (see Appendix Table A5).

Figure 4: Mean Stickers Shared, by Treatment and Age

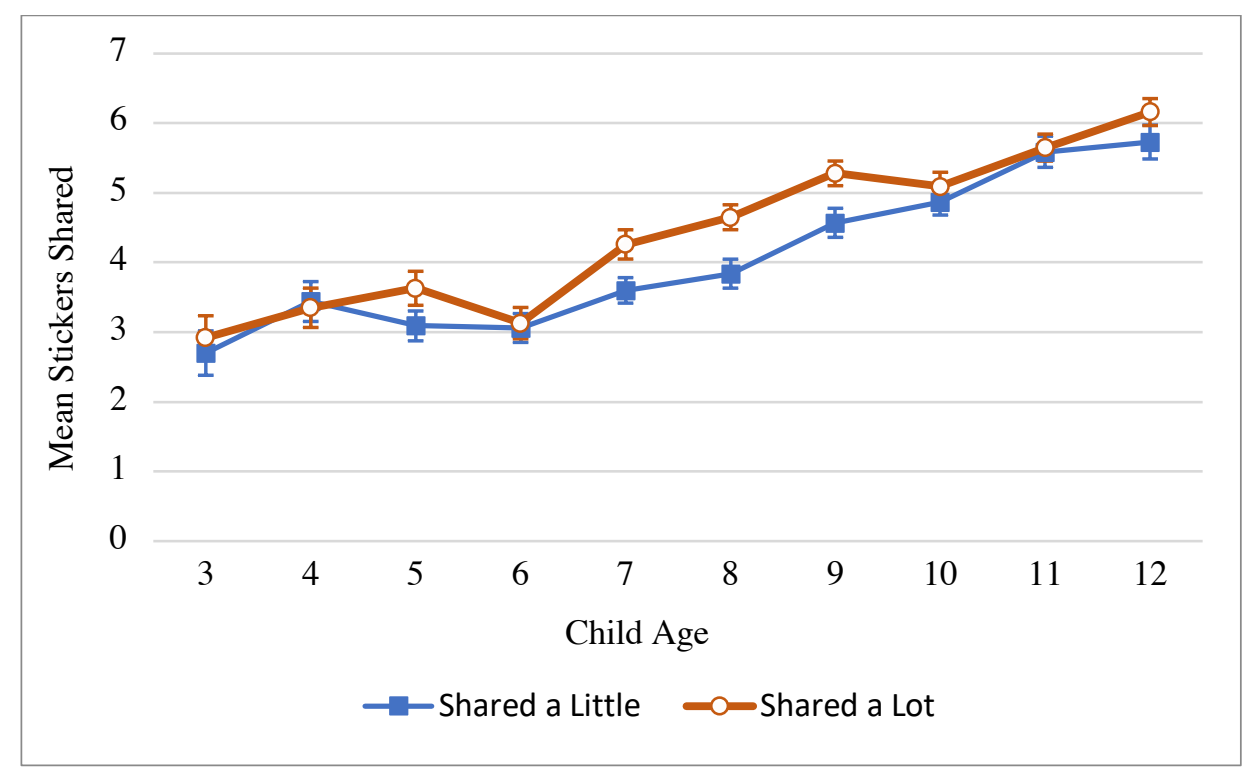


Note: This figure shows mean stickers shared by age. Bars depict standard error bars.

Table 1 provides ordinary least squares (OLS) regressions with sharing in the second dictator game as the outcome variable. Specifications (1)-(3) include country dummy variables, while Specifications (4)-(5) include a control for the Hofstede score. In Specification (1), we included the baseline stickers shared as a control variable. We found that, as expected, baseline sharing was a strong and significant predictor of sharing in the second dictator game (Coefficient $=0.67, \mathrm{p}<0.001, \mathrm{eta}^{2}=0.36$ ). Appendix Table A6 provides additional regressions in which zerosharers (children who shared zero in the game) were omitted. We continued to observe similar treatment effects as in the main regressions.

In Specification (2) we added controls for child age and gender. In line with the trend observed in Figure 4, sharing behavior increased with age, though the effect size was small (Coefficient $=0.16, p<0.001$, eta $\left.^{2}=0.04\right)$. In Specification $(3)$ we added socioeconomic status controls, including the number of children in the household and mother's educational attainment (with less than 9 years of education as the omitted variable). While the coefficient on educational level of the mother was positive, suggesting that sharing is higher among higher SES children, this result was not statistically significant (Coefficient estimates $0.19,0.23,0.09$ and 0.30 , all p-values $>0.10$, eta ${ }^{2}<0.001$ ). Specification (4) also includes the country's Hofstede score (discussed later).

We also explored whether any demographic or socio-economic variables interacted with the treatment. We did not find strong evidence for interaction effects. For example, in Table A5, we looked separately at interactions of treatment with gender, mother's educational attainment, income and household size, and initial sharing level. None of these proved to be statistically significant, though we found suggestive evidence (significant at the $10 \%$ level) that girls were more influenced by treatment than boys. 


\section{Table 1: Treatment Effect Regression}

\begin{tabular}{|c|c|c|c|c|c|}
\hline & $\begin{array}{c}\text { (1) } \\
\text { Sharing }\end{array}$ & $\begin{array}{c}(2) \\
\text { Sharing }\end{array}$ & $\begin{array}{c}\text { (3) } \\
\text { Sharing }\end{array}$ & $\begin{array}{c}(4) \\
\text { Sharing }\end{array}$ & $\begin{array}{c}\text { (5) } \\
\text { Sharing }\end{array}$ \\
\hline Share Treatment & $\begin{array}{c}0.46^{* * * *} \\
(0.09)\end{array}$ & $\begin{array}{c}0.42 * * * \\
(0.08)\end{array}$ & $\begin{array}{c}0.42 * * * \\
(0.09)\end{array}$ & $\begin{array}{c}0.42 * * * \\
(0.08)\end{array}$ & $\begin{array}{c}0.56 * * * \\
(0.16)\end{array}$ \\
\hline Baseline sharing & $\begin{array}{c}0.67 * * * \\
(0.02)\end{array}$ & $\begin{array}{c}0.60 * * * \\
(0.02)\end{array}$ & $\begin{array}{c}0.60 * * * \\
(0.02)\end{array}$ & $\begin{array}{c}0.60 * * * \\
(0.02)\end{array}$ & $\begin{array}{c}0.60 * * * \\
(0.02)\end{array}$ \\
\hline Age & & $\begin{array}{c}0.16^{* * * *} \\
(0.02)\end{array}$ & $\begin{array}{c}0.18^{* * * *} \\
(0.02)\end{array}$ & $\begin{array}{c}0.16^{* * * *} \\
(0.02)\end{array}$ & $\begin{array}{c}0.16^{* * *} \\
(0.02)\end{array}$ \\
\hline Female & & $\begin{array}{l}-0.01 \\
(0.08)\end{array}$ & $\begin{array}{l}-0.03 \\
(0.09)\end{array}$ & $\begin{array}{l}-0.01 \\
(0.08)\end{array}$ & $\begin{array}{l}-0.01 \\
(0.08)\end{array}$ \\
\hline Children in Household & & & $\begin{array}{l}-0.04 \\
(0.05)\end{array}$ & & \\
\hline Mother: 9-12 years education & & & $\begin{array}{c}0.19 \\
(0.22)\end{array}$ & & \\
\hline Mother: $13-16$ years education & & & $\begin{array}{c}0.24 \\
(0.23)\end{array}$ & & \\
\hline Mother: Bachelor's Degree & & & $\begin{array}{c}0.09 \\
(0.22)\end{array}$ & & \\
\hline Mother: Graduate level degree & & & $\begin{array}{c}0.30 \\
(0.23)\end{array}$ & & \\
\hline Hofstede Score & & & & $\begin{array}{l}0.01 * * \\
(0.00)\end{array}$ & $\begin{array}{l}0.01 * * \\
(0.00)\end{array}$ \\
\hline Hofstede $\mathrm{x}$ Treat & & & & & $\begin{array}{l}-0.00 \\
(0.00)\end{array}$ \\
\hline Constant & $\begin{array}{c}1.65^{* * * *} \\
(0.20)\end{array}$ & $\begin{array}{c}0.60 * * * \\
(0.23)\end{array}$ & $\begin{array}{c}0.39 \\
(0.34)\end{array}$ & $\begin{array}{c}0.22 \\
(0.22)\end{array}$ & $\begin{array}{c}0.15 \\
(0.23)\end{array}$ \\
\hline Country Dummy Variables & YES & YES & YES & NO & NO \\
\hline $\begin{array}{l}\text { Observations } \\
\text { R-squared }\end{array}$ & $\begin{array}{c}2,331 \\
0.40 \\
\end{array}$ & $\begin{array}{c}2,331 \\
0.43 \\
\end{array}$ & $\begin{array}{c}2,119 \\
0.43 \\
\end{array}$ & $\begin{array}{c}2,331 \\
0.43 \\
\end{array}$ & $\begin{array}{c}2,331 \\
0.43 \\
\end{array}$ \\
\hline
\end{tabular}

Notes: Ordinary Least Squares (OLS) regression on sharing in the second dictator game. The omitted category for education is "Less than 9 years". Standard errors in parentheses. Specifications (1)-(3) include country controls; specifications (4)-(5) do not. $* * * p<0.01, * * p<0.05, * p<0.1$

In Table A5, we also split the sample into three groups: 0,1 , or 2 sharers; 8,9 and 10 sharers, and everyone else. We did not find a significant interaction term on 0,1 or 2 sharers with treatment, suggesting that children who initially shared 0,1 or 2 did not differ much from children who initially shared 3-7 in terms of the impact of the treatment. However, we did find that children 
who shared 8, 9 or 10 initially were negatively influenced by the treatment (coefficient significant at the $5 \%$ level). This is intuitive since the "shared a lot" treatment suggests a sharing number of 6, and children who were already sharing more than this would not have been influenced by this treatment to increase their sharing.

Finally, an interesting question is whether the treatment results in more children changing their decision from the first dictator game to the second one. The proportion of children who changed their decision overall was $63 \%$. This result did not seem to be affected by the treatment since in the "shared a little" condition the proportion changing was $64 \%$ and in the "shared a lot condition the proportion changing was $62 \%($ Chi2 $\mathrm{p}$-value $=0.36)$. This suggests that the result we observed was not driven by a few children drastically changing their decision.

Given that the apparent differences in treatment effects by age were displayed in Figure 4, in appendix Table A7 we conducted separate regressions for children ages 3-5, 6-9 and 10-12. We found that the "shared a lot" treatment increases the number of stickers shared by 0.35 to 0.45 stickers. The largest and most significant treatment effect was concentrated in the 6-9-year-old age group (See specification 2, Coefficient $=0.45, \mathrm{p}<0.001$, eta ${ }^{2}=0.01$ ). However, we could not conclude statistically significant differences across the age groups (post-estimation test $p$-values when comparing the coefficients are above 0.10 ) and as noted earlier, the interaction term of age and treatment when age entered linearly in the regression was insignificant (see Table A5).

\subsection{Cross-Country Analysis}

We next evaluated our results across countries. Countries were very similar with respect to age, gender, and number of children in household. Summary statistics by country are presented in appendix Table A8. Countries differed somewhat on various dimensions. For example, with 
respect to baseline sharing rates, children from South Africa shared the least stickers $(M=2.76$, $\mathrm{SE}=0.17)$ and children from the United States shared the most stickers $(\mathrm{M}=4.93, \mathrm{SE}=0.19)$. These numbers are in line with related work that used a different cross-cultural sample (Cowell et al., 2017). For example, similar to us, Cowell et al. (2017) found lower sharing rates in South Africa and Turkey, but higher sharing rates in Canada, China and the United States.

Figure 5 provides the means of sharing behavior by treatment and country, with countries sorted from left to right by their Hofstede I/C index (individualist - collectivist). Note that direct comparisons across countries should be completed with caution, since the samples were not representative by country. Treatment effects were observed in seven countries: Canada, Norway, South Africa, Chile, China, Colombia and Cuba. Treatment effects were not observed in the United States, Argentina, Turkey, Mexico or Taiwan. Thus, while overall, we observed an effect of the "shared a lot" treatment, it was not observed in all countries. Moreover, there was no discernible individual-collectivism pattern either in overall sharing rates or in the effect of the treatment. For example, we would have expected the most individualist countries to share least; yet children in the United States shared over 5 stickers on average. We might also have expected more collectivist countries to be more responsive to treatment, yet we saw treatment effects of similar sizes in more individualist countries (e.g., Canada, Norway) as in more collectivist countries (e.g., China, Cuba).

In support of this visual evidence, Specification (5) in Table 1 shows a non-significant interaction of Hofstede with the share treatment (meaning that we do not find an association of the Hofstede score with treatment effects). Table A9 in the appendix provides a regression that includes country controls and country-treatment interaction terms. While this regression showed that countries do differ in their sharing rates and in their treatment effects, the pattern of differences did not align with the individualist/collectivist construct. 


\section{Figure 5: Treatment Effects by Country}

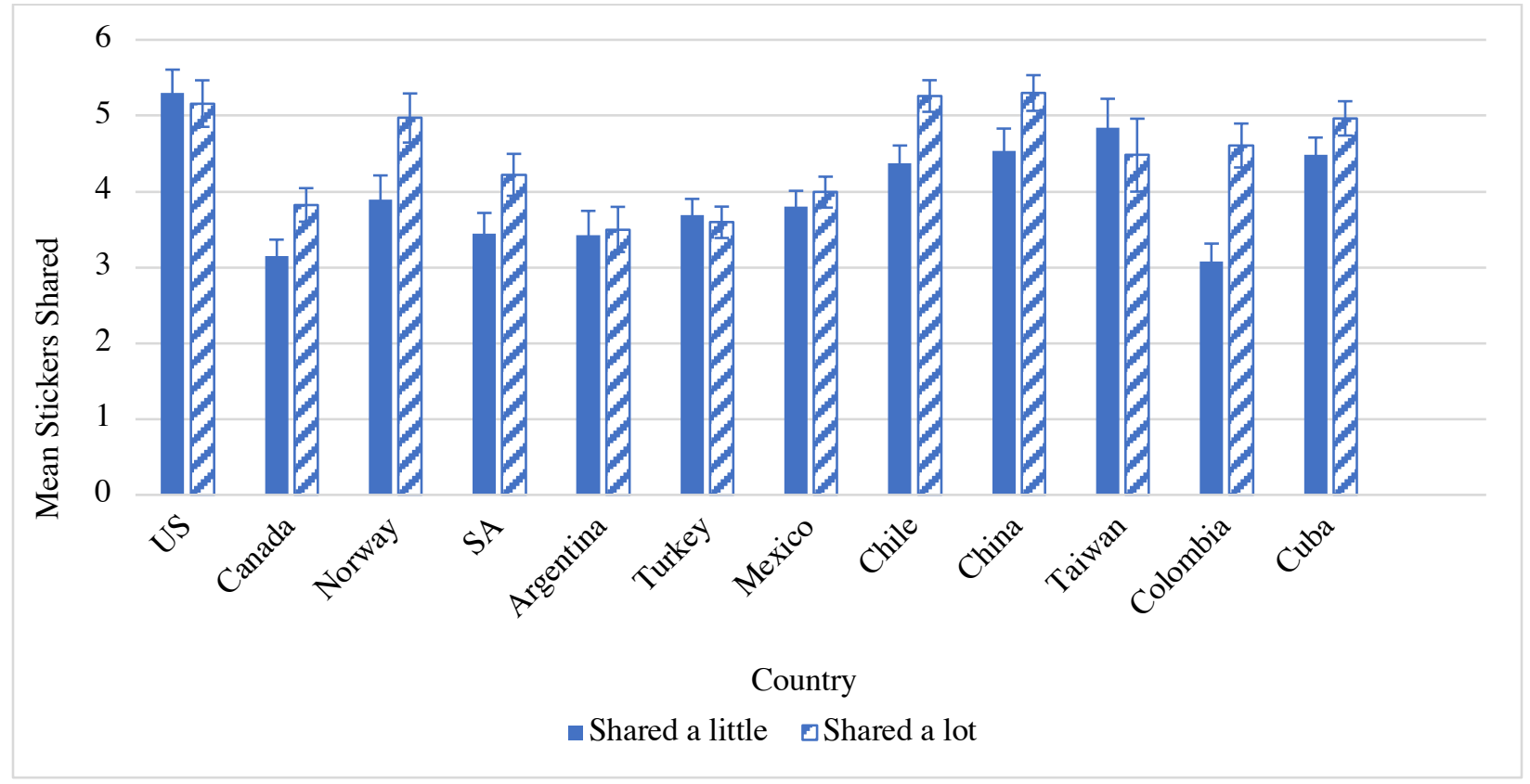

Note: This figure reports a bar charts of sharing, by treatment and country. Bars depict standard errors.

In the appendix, we also provide figures similar to Figures 2-5 by country (see Figures A3A8). The age distribution of participants by country looked similar to that of the overall sample. The modal sharing rate of 5 was most pronounced in Chile, China, Cuba, Mexico, Norway, Taiwan, Turkey and the US. Argentina and South Africa had the largest number of zero-sharers at baseline. Increases in sharing with age were observed in nearly all countries. Treatment effects (when observed) were most often observed in the middle age range (6-9 years old).

\section{Conclusion}

A key part of interacting in the social environment is participating in cooperative activity and responding to information about peers. A large body of literature has shown that helping and sharing behavior is present at very young ages and increases with age (e.g. Warneken and Tomasello, 2007; Fehr et al., 2008). However, most related work recruited children from WEIRD 
populations. A key element of these findings is the continuity of age-related increases in sharing regardless of whether the population was WEIRD or not. We conducted dictator game experiments in which children have the opportunity to share up to 10 stickers with another child. We found strong evidence that sharing increases with age, which was observed across all 12 countries in our study. Several potential explanations for this robust age-related development in sharing across cultures are possible. Some have argued that across this age-range, children become increasingly interested in appearing fair to others, thus explaining the shift towards equality in sharing (e.g., Shaw et al., 2014). Others have argued that the apparent shift in first-person resource allocation may be due to decreasing salience of the rewards, namely older children are not as interested in the stickers, resulting in increased giving, not as a prosocial act per-se, but as a measure of giving away undesirable resources (Gummerum, Yanoch, Keller, Parsons, \& Hummel, 2010). These explanations are not mutually exclusive, since both mechanisms could be drivers of the patterns of behavior we observed across ages. Our use of the Dictator game in the present study makes it difficult to identify these mechanisms directly. However, we have suggestive evidence in Appendix Figure A3 that both mechanisms could be at play. First, we see a strong increase across age in the decision to share at the fifty-fifty split. Second, we see some evidence that children are more likely to share more than half of their endowment as they get older. Future research should investigate these questions more directly.

A large and historic literature has documented the role of peer observation and peer opinions in motivating human behaviors, from children's aggression towards a BoBo Doll (e.g., Bandura, 1977) to adults conformity to incorrect responses in large groups (e.g., Asch and Guetzkow, 1951). In developmental psychology, the role of peers in broad development has been well studied (e.g., Hartup and Moore, 1990), and is documented to begin in early childhood and 
show marked additional influence throughout middle childhood and through adolescence on conformity (Walker \& Adrade, 1996), deviant behaviors (Keenan and Shaw, 1997), and potentially in prosociality. With some exceptions, most of this literature has used self-reported preferences and hypothetical situations or naturalistic observation. In our study, we specifically told children about the sharing behavior of another child and asked them to choose how many stickers to share. We found that telling children about another child who "shared a lot" increased the amount shared relative to telling children about another child who "shared a little." We found some evidence that this treatment effect was due to anchoring, since children increased their willingness to share 1 sticker in the "shared a little" treatment (where 1 is the model) and willingness to share 6 stickers in the "shared a lot" treatment (where 6 is the model). The treatment effect was most pronounced at ages 6-9, indicating a potential increased susceptibility to peer influence in later childhood. However, it should be noted that the effect was not statistically significantly different between children ages 6-9 and children ages 3-5 or 10-12. Importantly, one limitation of the current study is that children's sharing in the treatment conditions may have been influenced by both the anchor/peer influence aspect and their intrinsic need to remain consistent in their resource allocations. Alternatively, it is also possible that children who engaged in greater sharing in the baseline Dictator game felt licensed to be more selfish in the treatment condition (Merritt, Effron, and Monin, 2010). In either case, there is no reason to believe that children randomly assigned to the treatment conditions would have systematically differed on these motivations for sharing, indeed evidence of similarity in baseline Dictator sharing in our results further supports this notion.

Given that our study included 12 countries, it was important to examine whether there were patterns of cross-country differences. We hypothesized that social information would be more influential in collectivist - versus individualist - countries. To evaluate this hypothesis, we 
compared treatment effects for countries of different individualist/collectivist (I/C) scores. We did find that countries differed in the effect of the treatment (with some countries not displaying an effect at all) but we did not find systematic differences with respect to the I/C index. There are at least two possibilities that prevented us from obtaining a significant individual-collectivism effect. One possibility is that this index might be too general to have an indirect effect on children and their socialization. Several authors have indeed argued that the Hofstede Index and I/C scores do not adequately account for cultural differences (e.g., Baskerville, 2003). The second possibility is that although the countries involved differ from each other in terms of individual-collectivism, the children's parents' tendency might not be consistent with their country's tendency (Green, Deschamps, and Paez, 2003). Several large scale studies have indicated that individual level differences within a single society on individualist-collectivist tendencies are much larger than between country differences on individualist-collectivist scales. Future research into I/C differences might benefit from using a family-level analysis of individualism/collectivism or interdependence/independence, rather than a cultural level indicator.

Our study has several limitations. First, children were asked to share in the presence of an adult. This generates a very controlled setting, which could have possibly resulted in very different decisions than with no control or no adult presence. This could explain some of the absent effects when comparing individualist and collectivist countries. Related work could consider conducting observational studies cross-culturally to better document the sharing behavior of children in their natural setting. Another concern is the imbalance across treatments by some demographic characteristics and baseline sharing behavior. While we controlled for these variables in our regressions, these two groups could have differed in other systematic ways that were not observed. To explore this further, we conducted a replication of Table 1 excluding the two countries where 
there were significant age imbalance (Colombia and Turkey). This is reported in Table A10, and qualitative results did not change.

Taken together, results from this cross-national study indicate two important levels of continuity. First and foremost, across both WEIRD and non-WEIRD populations, children shared increased resources with an anonymous other as they aged from 3-12. While there were certainly country level differences in sharing that mirror previous cross-national investigations using similar tasks (e.g., Cowell et al., 2017; Huppert et al., 2019), the age-related linear relation was similar. Second, the influence of peers was consistent across most countries and ages. Contrary to our hypotheses that children from collectivist countries and/or in older age groups would be more susceptible to the reported actions of their peers, all children appeared to modulate their actions based on how much or how little a peer was stated to have shared. These results suggest a similarity in the degree to which social information and learning are integrated into computations of sharing across many nations and a large age range.

Acknowledgements: This study was supported by a grant from the John Templeton Foundation (The Science of Philanthropy Initiative) to Dr. Jean Decety. Dr. Anya Samek was also supported by this grant as well as by the Research Council of Norway through its Centres of Excellence Scheme, FAIR project No 262675. We thank the research assistants in all countries who helped in data collection and the many families and children who participated. 


\section{References}

Almås, I., Cappelen, A. W., Sørensen, E.Ø., \& Tungodden, B. (2010). Fairness and the Development of Inequality Acceptance. Science, 328(5982), 1176-1178.

Andreoni, J., Erard, B., \& Feinstein, J. (1998). Tax compliance. Journal of Economic Literature, 36(2), 818-860.

Asch, S. E., \& Guetzkow, H. (1951). Effects of group pressure upon the modification and distortion of judgments. Documents of Gestalt Psychology, 222-236.

Bar-Tal, D., Raviv, A., \& Leiser, T. (1980). The development of altruistic behavior: Empirical evidence. Developmental Psychology, 16(5), 516-524.

Bandura, A. (1977). Social learning theory. Englewood Cliffs, NJ: Prentice-Hall.

Banerjee, R. (2002). Children's understanding of self-presentational behavior: Links with mentalstate reasoning and the attribution of embarrassment. Merrill-Palmer Quarterly, 378-404.

Baskerville, R. F. (2003). Hofstede never studied culture. Accounting, Organizations and Society, 28(1), 1-14.

Bauer, M., Chytilová, J., \& Pertold-Gebicka, B. (2014). Parental background and other-regarding preferences in children. Experimental Economics, 17(1), 24-46.

Bauman, K. E., \& Ennett, S. T. (1996). On the importance of peer influence for adolescent drug use: Commonly neglected considerations. Addiction, 91(2), 185-198.

Ben-Ner, A., List, J. A., Putterman, L., \& Samek, A. (2017). Learned generosity? An artefactual field experiment with parents and their children. Journal of Economic Behavior \& Organization, 143, 28-44.

Benenson, J. F., Pascoe, J., \& Radmore, N. (2007). Children's altruistic behavior in the dictator game. Evolution and Human Behavior, 28(3), 168-175.

Bereby-Meyer, Y., \& Fiks, S. (2013). Changes in Negative Reciprocity as a Function of Age. Journal of Behavioral Decision Making, 26(4), 397-403.

Berndt, T. J. (1979). Developmental changes in conformity to peers and parents. Developmental Psychology, 15(6), 608-616.

Blake, P. R., \& McAuliffe, K. (2011). "I had so much it didn't seem fair": Eight-year-olds reject two forms of inequity. Cognition, 120(2), 215-224.

Blake, P. R., McAuliffe, K., \& Warneken, F. (2014). The developmental origins of fairness: The knowledge-behavior gap. Trends in Cognitive Sciences, 18(11), 559-561.

Blake, P. R., Corbit, J., Callaghan, T. C., \& Warneken, F. (2016). Give as I give: Adult influence on children's giving in two cultures. Journal of Experimental Child Psychology, 152, 149-160.

Bronfenbrenner, U. (1979). Contexts of child rearing: Problems and prospects. American Psychologist, 34, 844-850.

Cappelen, A. W., List, J. A., Samek, A., \& Tungodden, B. (2016). The Effect of Early Education on Social Preferences (No. w22898). National Bureau of Economic Research.

Charities Aid Foundation, World Giving Index Reports. (2018). World Giving Index 2018. Charities Aid Foundation.

Chassin, L., Presson, C. C., Sherman, S. J., Montello, D., \& McGrew, J. (1986). Changes in peer and parent influence during adolescence: Longitudinal versus cross-sectional perspectives on smoking initiation. Developmental Psychology, 22(3), 327.

Cowell, J. M., \& Decety, J. (2015). The neuroscience of implicit moral evaluation and its relation to generosity in early childhood. Current Biology, 25(1), 93-97. 
Cowell, J. M., Lee, K., Malcolm-Smith, S., Selcuk, B., Zhou, X., \& Decety, J. (2017). The development of generosity and moral cognition across five cultures. Developmental Science, 20(4), e12403.

Croson, R., \& Shang, J. Y. (2008). The impact of downward social information on contribution decisions. Experimental Economics, 11(3), 221-233.

de Guzman, M. R. T., Do, K. A., \& Kok, C. M. (2014). The Cultural Contexts of Children's Prosocial Behaviors. Prosocial Development: A Multidimensional Approach, 222-235.

Devanath, S. (2010). Parental Attitudes and Children's Sharing Behavior: How Socialization Relates to Early Prosocial Development (Doctoral dissertation, University of Pittsburgh).

Dishion, T. J. (2000). Cross-setting consistency in early adolescent psychopathology: Deviant friendships and problem behavior sequelae. Journal of personality, 68(6), 1109-1126.

Eisenberg, N., Hertz-Lazarowitz, R., \& Fuchs, I. (1990). Prosocial Moral Judgment in Israeli Kibbutz and City Children: A Longitudinal Study. Merrill-Palmer Quarterly, 36(2), 273-285.

Engel, C. (2011). Dictator Games: A Meta Study. Experimental Economics, 14(4), 538-610.

Fehr, E., Bernhard, H., \& Rockenbach, B. (2008). Egalitarianism in Young Children. Nature, 454(7208), 1079-1083.

Fehr, E., Glätzle-Rützler, D., \& Sutter, M. (2013). The development of egalitarianism, altruism, spite and parochialism in childhood and adolescence. European Economic Review, 64, 369383.

Flook, L., Goldberg, S. B., Pinger, L., \& Davidson, R. J. (2015). Promoting prosocial behavior and self-regulatory skills in preschool children through a mindfulness-based kindness curriculum. Developmental Psychology, 51(1), 44-51.

Foulkes, L., Leung, J. T., Fuhrmann, D., Knoll, L. J., \& Blakemore, S. (2018). Age differences in the prosocial influence effect. Developmental Science, $21(6)$, e12666.

Gardner, M., \& Steinberg, L. (2005). Peer Influence on Risk Taking, Risk Preference, and Risky Decision Making in Adolescence and Adulthood: An Experimental Study. Developmental Psychology, 41(4), 625-635.

Green, E. G., Deschamps, J. C., \& Paez, D. (2005). Variation of individualism and collectivism within and between 20 countries: A typological analysis. Journal of Cross-Cultural Psychology, 36(3), 321-339.

Gummerum, M., Hanoch, Y., Keller, M., Parsons, K., \& Hummel, A. (2010). Preschoolers' allocations in the dictator game: The role of moral emotions. Journal of Economic Psychology, 31(1), 25-34.

Harris, J. R. (1998). The nurture assumption: Why children turn out the way they do. Adolescence, $33,960$.

Hartup, W. \& Moore, S. (1990). Early peer relations: Developmental significance and prognostic implications. Early Childhood Research Quarterly, 5, 1-17.

Haun, D. B., \& Tomasello, M. (2011). Conformity to peer pressure in preschool children. Child Development, 82(6), 1759-1767.

Henrich, J., Heine, S. J., \& Norenzayan, A. (2010). The weirdest people in the world? Behavioral and Brain Sciences, 33(2-3), 61-83.

Hofstede, G. H., Hofstede, G. J., \& Minkov, M. (2010). Cultures and organizations, software of the mind. Intercultural cooperation and its importance for survival. McGraw-Hill, London.

House, B., Henrich, J., Sarnecka, B., \& Silk, J. B. (2013). The development of contingent reciprocity in children. Evolution and Human Behavior, 34(2), 86-93. 
Huppert, E., Cowell, J. M., Cheng, Y., Contreras-Ibáñez, C., Gomez-Sicard, N., Gonzalez-Gadea, M. L., Huepe, D., Ibáñez, A., Lee, K., Mahasneh, R. and Malcolm-Smith, S. (2019). The development of children's preferences for equality and equity across 13 individualistic and collectivist cultures. Developmental Science, 22(2), e12729.

Keenan, K., \& Shaw, D. (1997). Developmental and social influences on young girls' early problem behavior. Psychological Bulletin, 121(1), 95.

Khomych, O. (2018). The effectiveness of the project "learning to live together" in the context of the development of prosocial behavior of pupils 5-9 grades. Science Review, 1(8), 8-12.

Kogut, T., Slovic, P., \& Västfjäll, D. (2016). The effect of recipient identifiability and neediness on children's sharing behavior. Journal of Behavioral Decision Making, 29(4), 353-362.

List, J. A. (2011). The Market for Charitable Giving. Journal of Economic Perspectives, 25(2), 157-180.

Maccoby, E. E. (1990). Gender and relationships: A developmental account. American Psychologist, 45(4), 513.

Madsen, M. C., \& Shapira, A. (1977). Cooperation and Challenge in Four Cultures. The Journal of Social Psychology, 102(2), 189-195.

Malti, T., Gummerum, M., Ongley, S., Chaparro, M., Nola, M., \& Bae, N. Y. (2016). "Who is worthy of my generosity?" Recipient characteristics and the development of children's sharing. International Journal of Behavioral Development, 40(1), 31-40.

Maxwell, S. E., Lau, M. Y., \& Howard, G. S. (2015). Is psychology suffering from a replication crisis? What does "failure to replicate" really mean? American Psychologist, 70(6), 487-498.

McAuliffe, Katherine, Nichola J. Raihani, and Yarrow Dunham. "Children are sensitive to norms of giving." Cognition 167 (2017): 151-159.

Merritt, A. C., Effron, D. A., \& Monin, B. (2010). Moral self-licensing: When being good frees us to be bad. Social and Personality Psychology Compass, 4(5), 344-357.

Mesurado, B., Richaud, M. C., Mestre, M. V., Samper-García, P., Tur-Porcar, A., Mesa, S. A., \& Viveros, E. F. (2014). Parental Expectations and Prosocial Behavior of Adolescents From Low-Income Backgrounds. Journal of Cross-Cultural Psychology, 45(9), 1471-1488.

Nielsen, M., Haun, D., Kärtner, J., \& Legare, C. H. (2017). The persistent sampling bias in developmental psychology: A call to action. Journal of Experimental Child Psychology, 162, 31-38.

Olson, K. R., \& Spelke, E. S. (2008). Foundations of cooperation in young children. Cognition, $108(1), 222-231$.

Rao, N., \& Stewart, S. M. (1999). Cultural Influences on Sharer and Recipient Behavior: Sharing in Chinese and Indian Preschool Children. Journal of Cross-Cultural Psychology, 30(2), 219241.

Rushton, J. P. (1976). Socialization and the altruistic behavior of children. Psychological Bulletin, 83(5), 898-913.

Santamaría-García, H., González-Gada, M. L., Di Tella, R., Ibáñez, A., \& Sigman, M. (2018). The interplay between sharing behavior and beliefs about others in children during dictator games. Journal of Experimental Child Psychology, 166, 451-464.

Sebastián-Enesco, C., Hernández-Lloreda, M. V., \& Colmenares, F. (2013). Two and a half-yearold children are prosocial even when their partners are not. Journal of Experimental Child Psychology, 116(2), 186-198. 
Shang, J., \& Croson, R. (2009). A Field Experiment in Charitable Contribution: The Impact of Social Information on the Voluntary Provision of Public Goods. The Economic Journal, 119(540), 1422-1439.

Shapira, A., \& Madsen, M. C. (1969). Cooperative and Competitive Behavior of Kibbutz and Urban Children in Israel. Child Development, 40(2), 609-617.

Shapira, A., \& Madsen, M. C. (1974). Between- and within-group cooperation and competition among kibbutz and nonkibbutz children. Developmental Psychology, 10(1), 140-145.

Shaw, A., Montinari, N., Piovesan, M., Olson, K. R., Gino, F., \& Norton, M. I. (2014). Children develop a veil of fairness. Journal of Experimental Psychology General, 143(1), 363-375.

Sherif, M. (1954) The Robbers Cave experiment: Intergroup conflict and cooperation. Wesleyan University Press: Middletown, CT.

Steinberg, L., \& Silverberg, S. B. (1986). The vicissitudes of autonomy in early adolescence. Child Development, 841-851.

Steinberg, L., \& Monahan, K. C. (2007). Age Differences in Resistance to Peer Influence. Developmental Psychology, 43(6), 1531-543.

Stewart, S. M., \& McBride-Chang, C. (2000). Influences on Children's Sharing in a Multicultural Setting. Journal of Cross-Cultural Psychology, 31(3), 333-348.

Decety, J., \& Svetlova, M. (2012). Putting together phylogenetic and ontogenetic perspectives on empathy. Developmental Cognitive Neuroscience, 2, 1-24.

Triandis, H. C. (1996). The psychological measurement of cultural syndromes. American Psychologist, 51(4), 407-415.

Triandis, H. C. (2001). Individualism-Collectivism and Personality. Journal of Personality, 69(6), 907-924.

van Hoorn, J., Dijk, E. V., Meuwese, R., Rieffe, C., \& Crone, E. A. (2014). Peer Influence on Prosocial Behavior in Adolescence. Journal of Research on Adolescence, 26(1), 90-100.

Vandell, D. L. (2000). Parents, peer groups, and other socializing influences. Developmental Psychology, 36, 699-710.

Walker, M. B., \& Andrade, M. G. (1996). Conformity in the Asch task as a function of age. The Journal of Social Psychology, 136(3), 367-372.

Warneken, F., \& Tomasello, M. (2007). Helping and Cooperation at 14 Months of Age. Infancy, 11(3), 271-294.

Warneken, F., \& Tomasello, M. (2009). The roots of human altruism. British Journal of Psychology, 100(3), 455-471.

Winkleby, M. A., Jatulis, D. E., Frank, E., \& Fortmann, S. P. (1992). Socioeconomic status and health: How education, income, and occupation contribute to risk factors for cardiovascular disease. American Journal of Public Health, 82(6), 816-820.

Yagmurlu, B., \& Sanson, A. (2009). Parenting and temperament as predictors of prosocial behaviour in Australian and Turkish Australian children. Australian Journal of Psychology, 61(2), 77-88. 


\section{- Online Appendix -}

\section{Sample Selection}

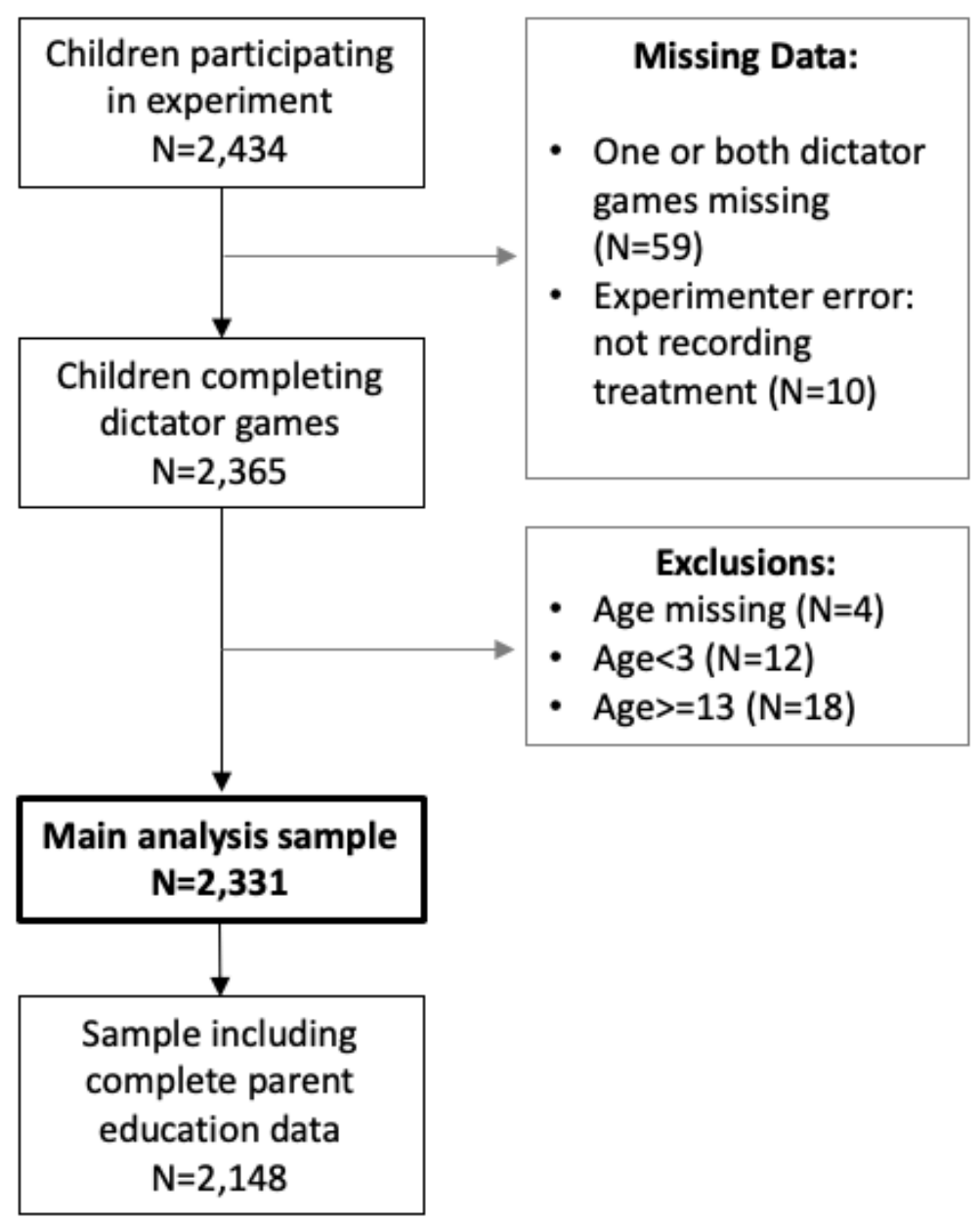




\section{2: Instructions}

\section{Baseline Dictator}

First, we are going to play a game with some stickers. Will you please pick out 10 stickers? (Empty bag of 30 stickers in front of child face up and allow child to select 10 stickers) Great! These are your stickers now. (Put 10 stickers in a row in front of the child.) Do you like your stickers? (Wait for child to affirm.) Great! Now we are ready to play the game!

I only have time today to give stickers to some of the girls and boys that are coming in to play games today. I won't be able to give stickers to everyone. In this game, you get to decide how many of your stickers you want to keep, and how many of your stickers you want to give to another girl or boy coming in today who does not get any stickers. You do not have to give any of your stickers away, but if you want to give some or all of your stickers away, you can. I will not know who gets the stickers that you give away and neither will you.

Any stickers you are going to keep, you will put them in your envelope here (place the envelope with the child's name written on it next to the child). Any stickers you want to give to another boy or girl, you will put in this envelope here (place the other envelope labeled "other boy or girl").

Can you show me which envelope is your envelope? That's right, this is your envelope (point to envelope with child's name). You take home the stickers in this envelope. Can you show me which envelope is the envelope for another boy or girl? That's right, this is the envelope for another girl/boy (point to the other envelope).

I'm going to cover my eyes now while you decide how many stickers you want to keep and how many you want to give away (Close and cover eyes and turn away from table to give child privacy to make their choice). You can tell me when you are finished. (Give the child about 1 minute, then say:) Ok, you have 10 seconds left to decide! (So that it doesn't take too long).

(Once child has finished choosing)

Great job!! Here are your stickers. You get to take these stickers home.

(Remember to count stickers later.)

\section{[ Tasks in Between ]}

\section{Social Comparison}

Check notes for which comparison game the child is supposed to play, read the script for the corresponding condition $(1=$ shared a little OR $2=$ shared a lot $)$

SHARED A LITTLE: 
Okay, now we're going to play the sticker game again. Will you please pick out 10 stickers? (Empty bag of 30 stickers in front of child face up and allow child to select 10 stickers) Great! These are your stickers now. (Put 10 stickers in a row in front of the child.) Do you like them? (Wait for child to affirm.) Great! Now we are ready to play the game!

There is another boy/girl (GENDER MATCHED) from your school that played the same sticker game today; they gave 1 sticker to another child and kept 9 for themselves. Now, it's your turn to play this game with a different boy or girl. Remember, you do not have to give any of your stickers away, but if you want to give some or all of your stickers away, you can.

Do you have any questions?

Any stickers you are going to keep, you will put them in your envelope here (place the envelope with the child's name written on it next to the child). Any stickers you want to give to another boy/girl who will not get to play this game, you will put in this envelope here (place the other envelope labeled "other boy or girl").

Can you show me which envelope is your envelope? That's right; this is your envelope (point to envelope with child's name). You take home the stickers in this envelope. Can you show me which envelope is the envelope for the other boy or girl? That's right; this is the envelope for the other girl/boy. (point to the other envelope).

I'm going to cover my eyes now while you decide how many stickers you want to keep and how many you want to give away (Close and cover eyes and turn away from table to give child privacy to make their choice). You can tell me when you are finished. (Give the child about 1 minute, then say:) Ok, you have 10 seconds left to decide! (So that it doesn't take too long).

(Once child has finished choosing)

Great job!! Here are your stickers. You get to take these stickers home.

(Remember to count stickers later.)

\section{SHARED A LOT:}

Okay, now we're going to play the sticker game again. Will you please pick out 10 stickers? (Empty bag of 30 stickers in front of child face up and allow child to select 10 stickers) Great! These are your stickers now. (Put 10 stickers in a row in front of the child.) Do you like them? (Wait for child to affirm.) Great! Now we are ready to play the game!

There is another boy/girl (GENDER MATCHED) from your school that played the same sticker game today; they gave 6 stickers to another child and kept 4 for themselves. Now, it's your turn to play this game with a different boy or girl. Remember, you do not have to give any of your stickers away, but if you want to give some or all of your stickers away, you can.

Do you have any questions? 
Any stickers you are going to keep, you will put them in your envelope here (place the envelope with the child's name written on it next to the child). Any stickers you want to give to another boy/girl who will not get to play this game, you will put in this envelope here (place the other envelope labeled "other boy or girl").

Can you show me which envelope is your envelope? That's right; this is your envelope (point to envelope with child's name). You take home the stickers in this envelope. Can you show me which envelope is the envelope for the other boy or girl? That's right; this is the envelope for the other girl/boy. (point to the other envelope).

I'm going to cover my eyes now while you decide how many stickers you want to keep and how many you want to give away (Close and cover eyes and turn away from table to give child privacy to make their choice). You can tell me when you are finished. (Give the child about 1 minute, then say:) Ok, you have 10 seconds left to decide! (So that it doesn't take too long).

(Once child has finished choosing)

Great job!! Here are your stickers. You get to take these stickers home.

(Remember to count stickers later.) 


\section{3: Additional Tables and Figures}

Figure A1: Histogram of Participant Age Distributions

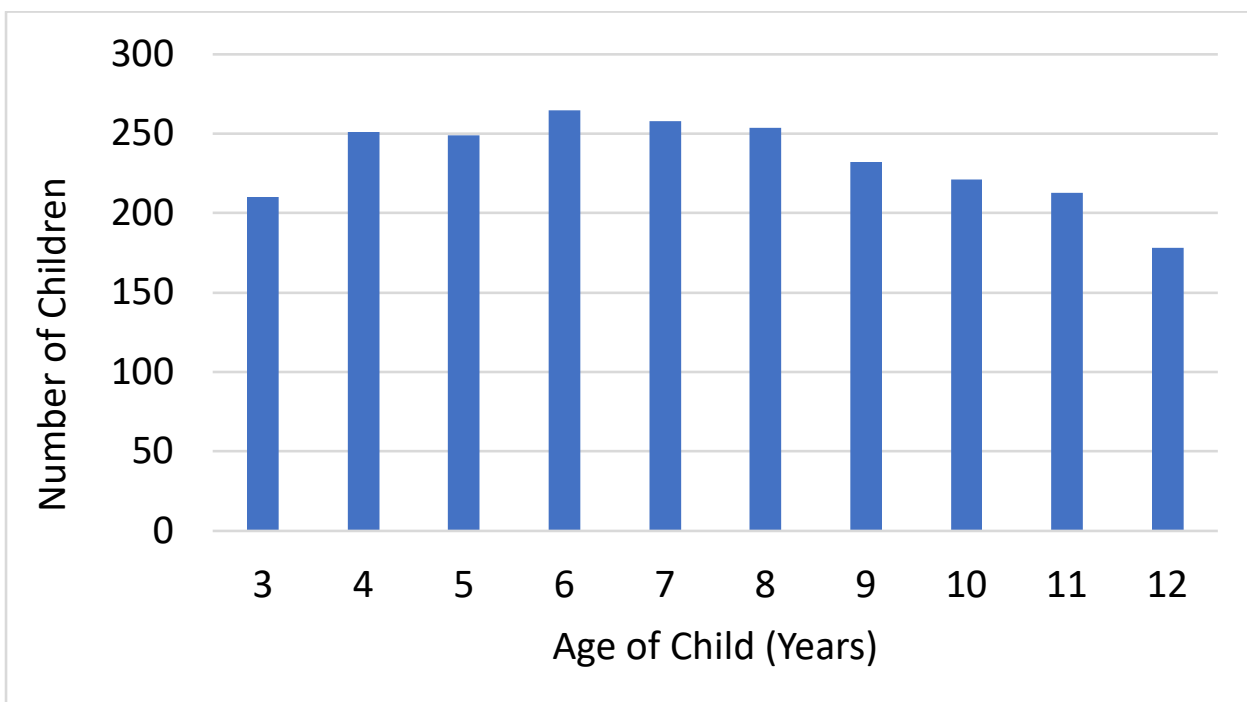

Figure A2: Distribution of Child Age by Country

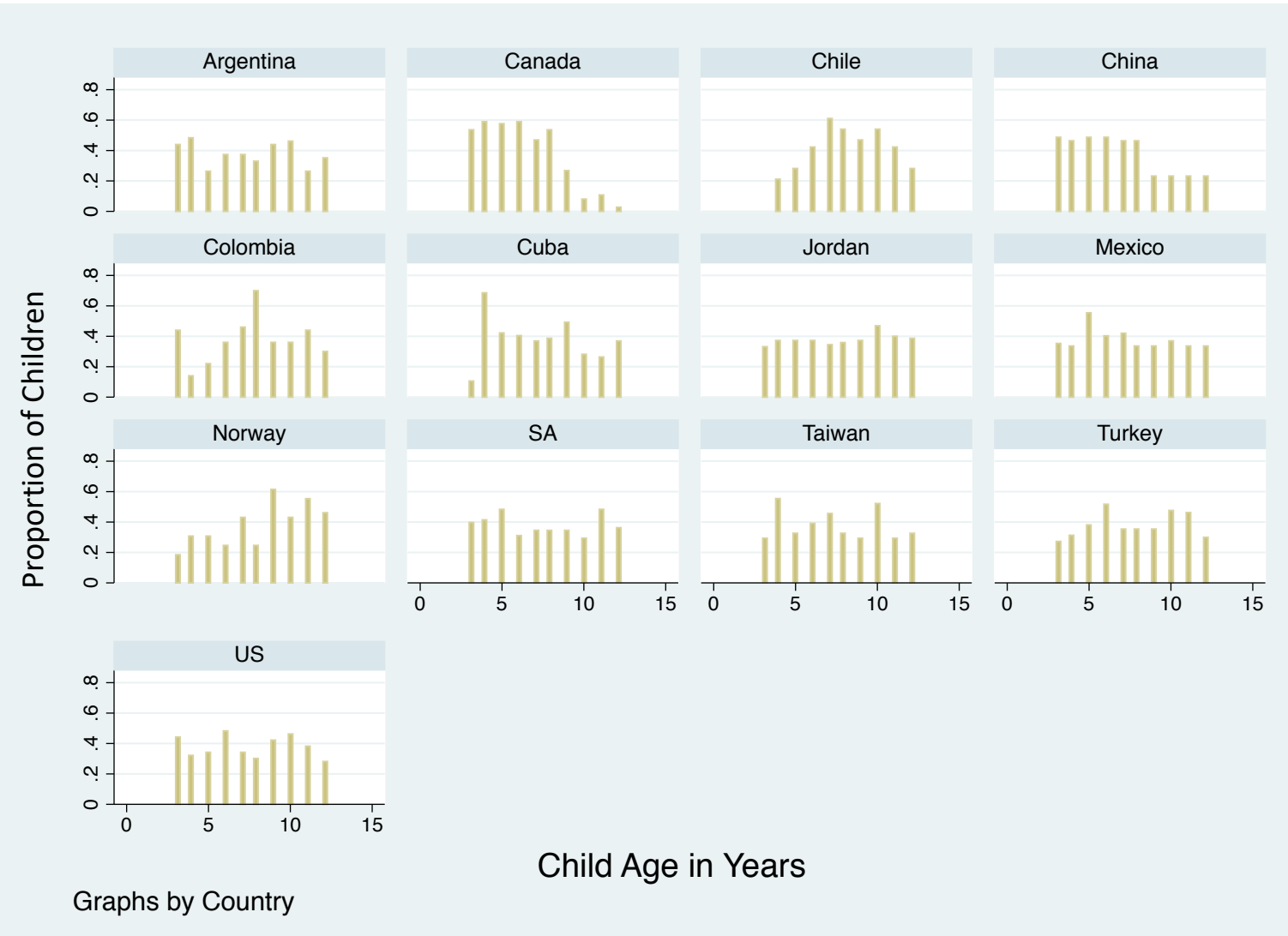


Figure A3: Distribution of Sharing by Age

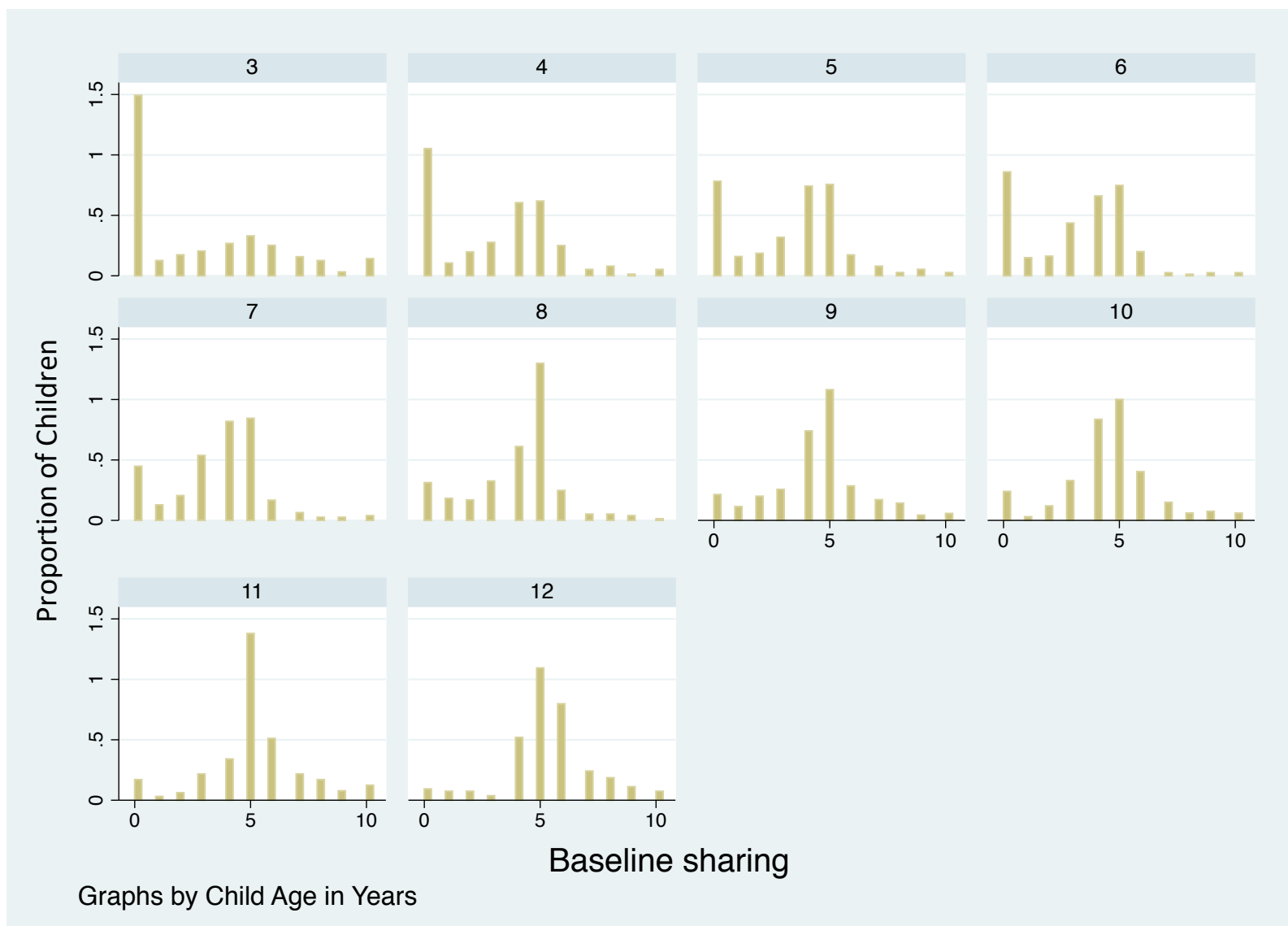




\section{Figure A4: Baseline Sharing by Country and Treatment}

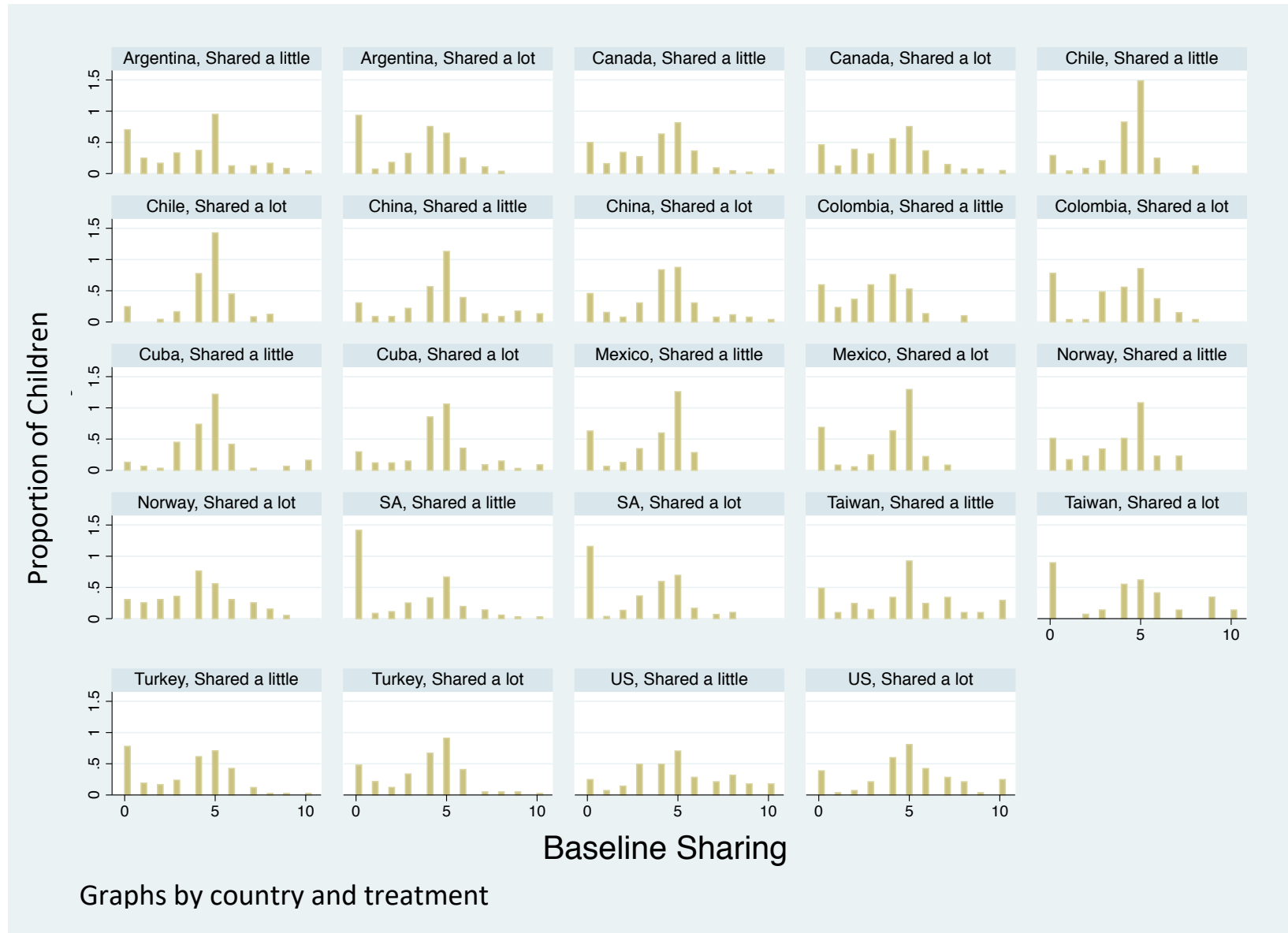


Figure A5: Baseline Sharing, by Age and Country

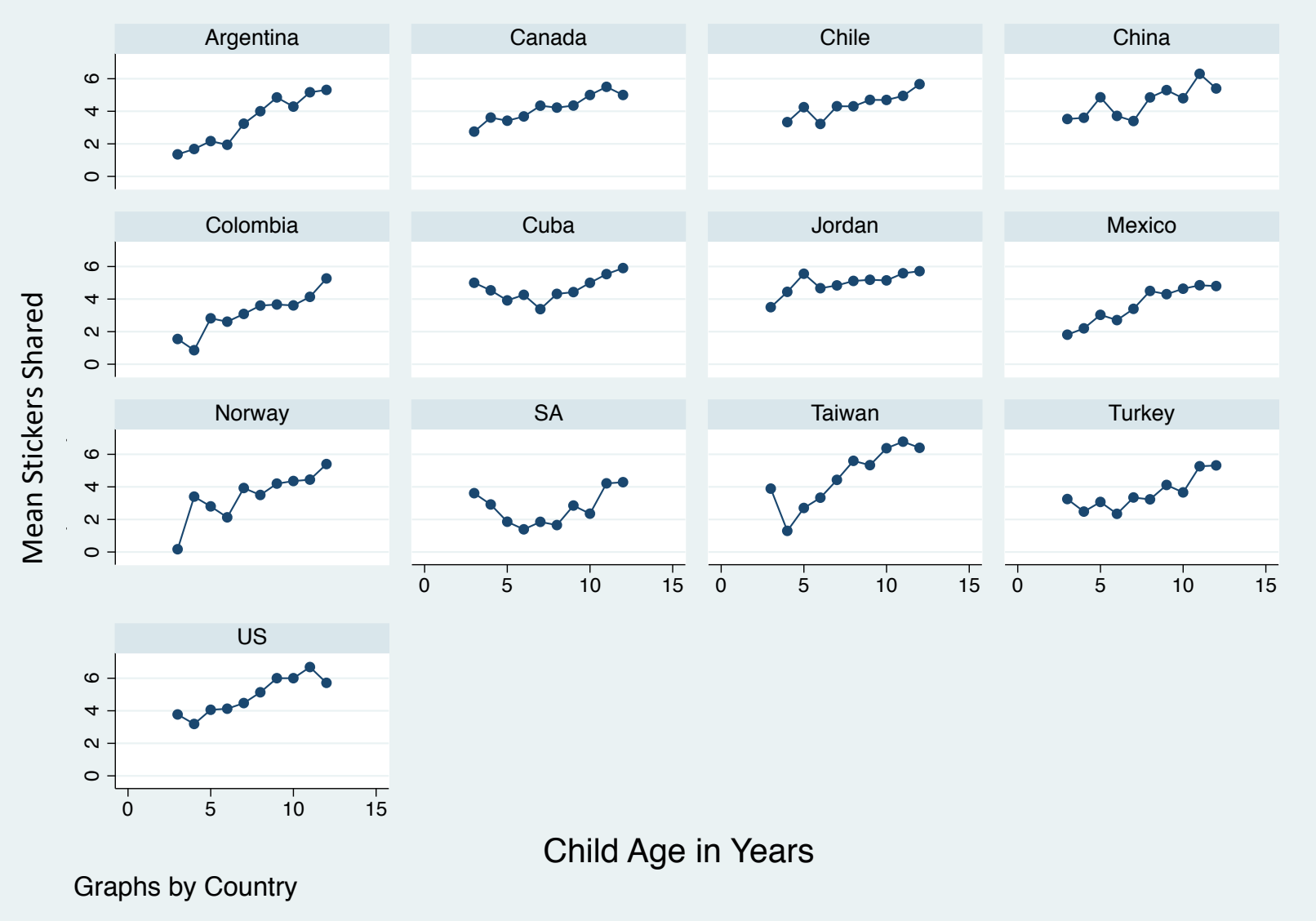


Figure A6: Sharing in Second Dictator Game, "Shared a Little" Treatment, by Country

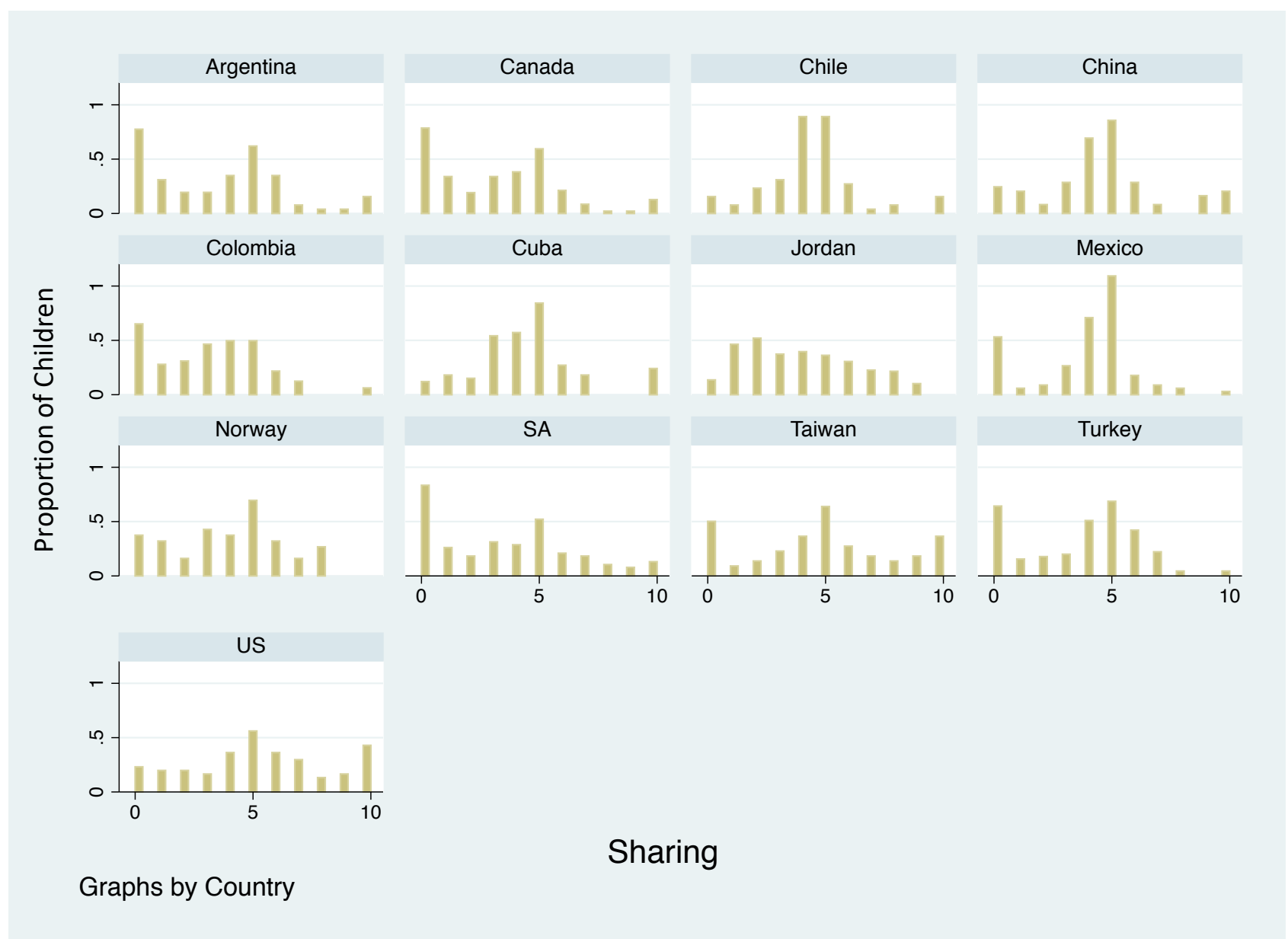


Figure A7: Sharing in Second Dictator Game, "Shared a Lot" Treatment, by Country

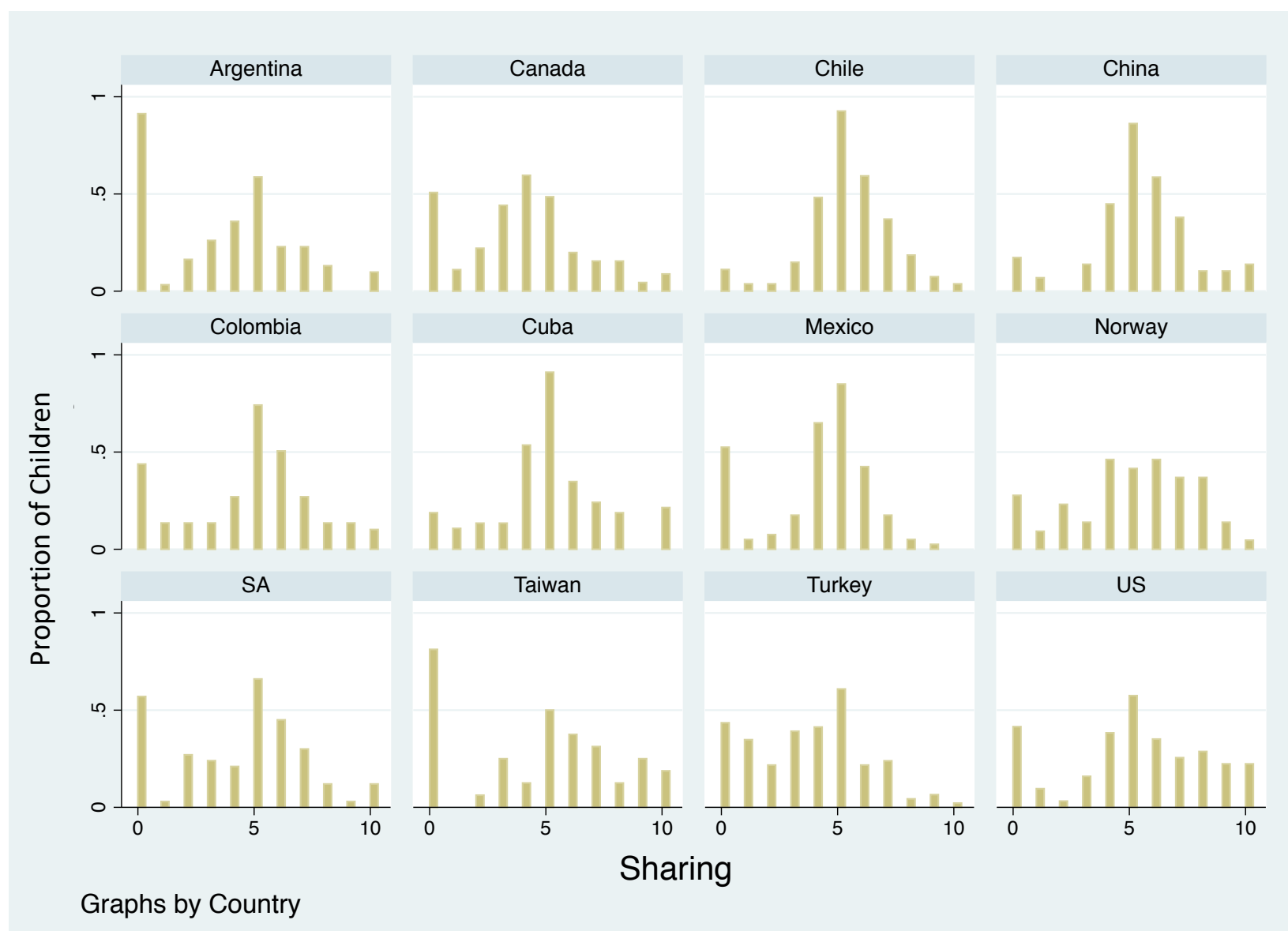


Figure A8: Sharing By Age, Treatment and Country

("Shared a little" is blue and "Shared a lot" is red)

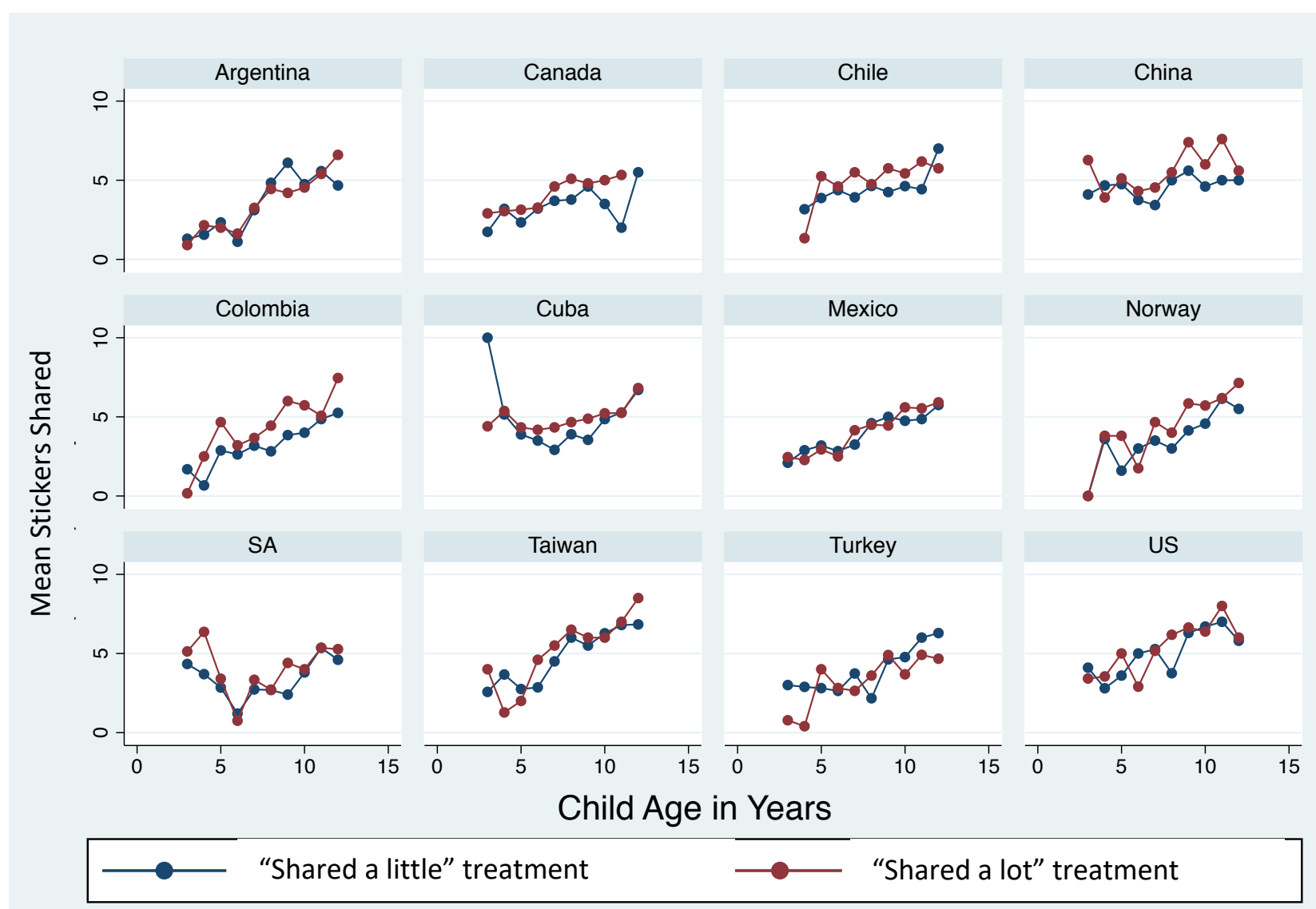

Graphs by Country 
Table A1: Descriptive Sample Statistics

\begin{tabular}{|l|c|}
\hline & All Countries \\
\hline Age & 7.68 \\
& $(0.06)$ \\
\hline \% Female & 51.48 \\
\hline Children in Household & 2.13 \\
& $(0.02)$ \\
\hline Mother: 0-8y education & 5.68 \\
\hline Mother: 9-12y education & 19.09 \\
\hline Mother: 13-16y education & 19.97 \\
\hline Mother: BS/BA & 31.98 \\
\hline Mother: Grad level & 23.28 \\
\hline Baseline Sharing & 3.84 \\
\hline Number of children & 2,331 \\
\hline
\end{tabular}

Notes: This table provides details on the sample. Standard errors of means are in parentheses. 
Table A2: Information about Recruitment by Country

\begin{tabular}{|c|c|c|c|c|c|}
\hline Country & City & $\begin{array}{l}\text { Population } \\
\text { Estimate }\end{array}$ & $\begin{array}{l}\text { Primary } \\
\text { Language }\end{array}$ & Recruitment method & Testing location \\
\hline USA & Chicago & $2,720,546$ & English & $\begin{array}{l}\text { Families recruited } \\
\text { through a database }\end{array}$ & $\begin{array}{l}\text { University laboratory } \\
\text { testing space }\end{array}$ \\
\hline Taiwan & Taipei & $2,691,000$ & $\begin{array}{l}\text { Mandarin } \\
\text { Chinese }\end{array}$ & $\begin{array}{l}\text { Families called } \\
\text { directly from the } \\
\text { laboratory }\end{array}$ & $\begin{array}{l}\text { University laboratory } \\
\text { testing space }\end{array}$ \\
\hline Mexico & Mexico City & $20,137,152$ & Spanish & $\begin{array}{l}\text { Families at primary } \\
\text { schools contacted } \\
\text { directly }\end{array}$ & $\begin{array}{l}\text { Testing room within } \\
\text { primary schools }\end{array}$ \\
\hline Colombia & $\begin{array}{l}\text { Bogota } \\
\text { Villavicencio }\end{array}$ & $\begin{array}{l}10,352,000 \\
506,000\end{array}$ & Spanish & $\begin{array}{l}\text { Families at primary } \\
\text { schools contacted } \\
\text { directly }\end{array}$ & $\begin{array}{l}\text { Testing room within } \\
\text { primary schools }\end{array}$ \\
\hline Argentina & Buenos Aires & $2,891,000$ & Spanish & $\begin{array}{l}\text { Families at primary } \\
\text { schools contacted } \\
\text { directly }\end{array}$ & $\begin{array}{l}\text { Testing room within } \\
\text { primary schools }\end{array}$ \\
\hline Canada & Toronto & $5,000,000$ & English & $\begin{array}{l}\text { Families recruited } \\
\text { through a database }\end{array}$ & $\begin{array}{l}\text { University laboratory } \\
\text { testing space }\end{array}$ \\
\hline South Africa & Cape Town & $3,774,000$ & $\begin{array}{l}\text { Afrikaans } \\
\text { \& English }\end{array}$ & $\begin{array}{l}\text { Families at primary } \\
\text { schools contacted } \\
\text { directly }\end{array}$ & $\begin{array}{l}\text { Testing room within } \\
\text { primary schools }\end{array}$ \\
\hline Chile & Santiago & $7,000,000$ & Spanish & $\begin{array}{l}\text { Families at primary } \\
\text { schools contacted } \\
\text { directly }\end{array}$ & $\begin{array}{l}\text { Testing room within } \\
\text { primary schools }\end{array}$ \\
\hline Norway & Bergen & 278,556 & Norwegian & $\begin{array}{l}\text { Families at primary } \\
\text { schools contacted } \\
\text { directly }\end{array}$ & $\begin{array}{l}\text { Testing room within } \\
\text { primary schools }\end{array}$ \\
\hline Cuba & Havana & $2,106,146$ & Spanish & $\begin{array}{l}\text { Families at primary } \\
\text { schools contacted for } \\
\text { recruitment at the } \\
\text { laboratory }\end{array}$ & $\begin{array}{l}\text { University laboratory } \\
\text { testing space }\end{array}$ \\
\hline China & Guangzhou & $12,000,000$ & $\begin{array}{l}\text { Mandarin } \\
\text { Chinese }\end{array}$ & $\begin{array}{l}\text { Families at primary } \\
\text { schools contacted } \\
\text { directly }\end{array}$ & $\begin{array}{l}\text { Testing room within } \\
\text { primary schools }\end{array}$ \\
\hline Turkey & $\begin{array}{l}\text { Istanbul } \\
\text { Izmir }\end{array}$ & $\begin{array}{l}14,804,116 \\
2,500,603\end{array}$ & Turkish & $\begin{array}{l}\text { Families at primary } \\
\text { schools contacted } \\
\text { directly and social } \\
\text { media recruitment }\end{array}$ & $\begin{array}{l}\text { Testing room within } \\
\text { primary schools }\end{array}$ \\
\hline
\end{tabular}


Table A3: Summary Statistics by Treatment

\begin{tabular}{|l|c|c|c|c|}
\hline & Shared a Little & Shared a Lot & Total & p-value \\
\hline Age & 7.54 & 7.83 & 7.68 & 0.01 \\
& $(0.08)$ & $(0.08)$ & $(0.06)$ & \\
\hline Female & 0.50 & 0.53 & 0.51 & 0.10 \\
\hline Children in Household & 2.14 & 2.11 & 2.13 & 0.49 \\
& $(0.03)$ & $(0.03)$ & $(0.02)$ & 0.39 \\
\hline Mother: 0-8 years education & 0.06 & 0.05 & 0.06 & 0.13 \\
\hline Mother: 9-12 years education & 0.20 & 0.18 & 0.19 & 0.25 \\
\hline $\begin{array}{l}\text { Mother: 13-16 years } \\
\text { education }\end{array}$ & 0.19 & 0.21 & 0.20 & 0.97 \\
\hline Mother: Bachelor's degree & 0.32 & 0.32 & 0.32 & 0.45 \\
\hline $\begin{array}{l}\text { Mother: Graduate level } \\
\text { degree }\end{array}$ & 0.22 & 0.24 & 0.23 & 0.70 \\
\hline Baseline Sharing & 3.83 & 3.87 & 3.85 & $(0.05)$ \\
\hline Number of children & 1,169 & 1,162 & 2,331 & \\
\hline
\end{tabular}

Note: This table reports summary statistics, by treatment. Standard errors are reported for means but not for frequencies.

Table A4: Formal Test of Anchoring

\begin{tabular}{lccccc}
\hline & $(1)$ & $(2)$ & $(3)$ & $(4)$ & $(5)$ \\
& Shared 1 & Shared 6 & Shared 1 & Shared 6 & Shared Equal \\
\hline Share Treatment & $-0.03^{* * *}$ & $0.03^{* *}$ & -0.01 & 0.01 & -0.00 \\
& $(0.01)$ & $(0.01)$ & $(0.01)$ & $(0.01)$ & $(0.02)$ \\
Baseline sharing & $-0.01^{* * *}$ & $0.01^{* * *}$ & & & \\
& $(0.00)$ & $(0.00)$ & & & $0.02^{* * *}$ \\
Age & 0.00 & $0.01^{* * *}$ & $-0.00^{* *}$ & $0.01 * * *$ & $(0.00)$ \\
& $(0.00)$ & $(0.00)$ & $(0.00)$ & $(0.00)$ & $0.24^{* * *}$ \\
Dictator shared equal & & & & & $(0.02)$ \\
Country Dummy Vars & YES & YES & YES & YES & YES \\
Constant & $0.13^{* * *}$ & -0.02 & $0.05^{* * *}$ & -0.01 & $0.06^{*}$ \\
& $(0.02)$ & $(0.03)$ & $(0.01)$ & $(0.02)$ & $(0.03)$ \\
& & & & & 2,331 \\
Observations & 2,331 & 2,331 & 2,331 & 2,331 & 0.09 \\
R-squared & 0.04 & 0.03 & 0.01 & 0.03 & \\
\hline
\end{tabular}

Notes: Ordinary Least Squares (OLS) regression on sharing in the second dictator game. The outcome variables are shared 1 or not (Cols 1 and 3), shared 6 or not (Cols 2 and 4) or shared an equal amount in the second dicatator game. $* * * p<0.01, * * p<0.05, * p<0.1$ 
Table A5: Interactions with Treatment

\begin{tabular}{|c|c|c|c|c|c|c|}
\hline & $\begin{array}{c}\text { (1) } \\
\text { Sharing }\end{array}$ & $\begin{array}{c}(2) \\
\text { Sharing }\end{array}$ & $\begin{array}{c}(3) \\
\text { Sharing }\end{array}$ & $\begin{array}{c}\text { (4) } \\
\text { Sharing }\end{array}$ & $\begin{array}{c}(5) \\
\text { Sharing } \\
\end{array}$ & $\begin{array}{c}(6) \\
\text { Sharing }\end{array}$ \\
\hline Share Treatment & $\begin{array}{c}0.20 \\
(0.25)\end{array}$ & $\begin{array}{l}0.26 * * \\
(0.12)\end{array}$ & $\begin{array}{c}0.51 \\
(0.37)\end{array}$ & $\begin{array}{c}0.57 * * * \\
(0.22)\end{array}$ & $\begin{array}{c}0.51^{* * * *} \\
(0.16)\end{array}$ & $\begin{array}{c}0.47 * * * \\
(0.11)\end{array}$ \\
\hline Baseline sharing & $\begin{array}{c}0.60 * * * \\
(0.02)\end{array}$ & $\begin{array}{c}0.61 * * * \\
(0.02)\end{array}$ & $\begin{array}{c}0.60 * * * \\
(0.02)\end{array}$ & $\begin{array}{c}0.60^{* * * *} \\
(0.02)\end{array}$ & $\begin{array}{c}0.62 * * * \\
(0.03)\end{array}$ & \\
\hline Age & $\begin{array}{c}0.15^{* * *} \\
(0.02)\end{array}$ & $\begin{array}{c}0.16^{* * * *} \\
(0.02)\end{array}$ & $\begin{array}{c}0.17 * * * \\
(0.02)\end{array}$ & $\begin{array}{c}0.17 * * * \\
(0.02)\end{array}$ & $\begin{array}{c}0.16^{* * * *} \\
(0.02)\end{array}$ & $\begin{array}{c}0.21 * * * \\
(0.02)\end{array}$ \\
\hline Female & $\begin{array}{l}-0.01 \\
(0.08)\end{array}$ & $\begin{array}{l}-0.16 \\
(0.12)\end{array}$ & $\begin{array}{l}-0.05 \\
(0.09)\end{array}$ & $\begin{array}{c}0.00 \\
(0.09)\end{array}$ & $\begin{array}{l}-0.02 \\
(0.08)\end{array}$ & $\begin{array}{l}-0.03 \\
(0.09)\end{array}$ \\
\hline Mother: 9-12 years education & & & $\begin{array}{c}0.33 \\
(0.29)\end{array}$ & & & \\
\hline Mother: $13-16$ years education & & & $\begin{array}{c}0.17 \\
(0.29)\end{array}$ & & & \\
\hline Mother: Bachelor's Degree & & & $\begin{array}{c}0.09 \\
(0.28)\end{array}$ & & & \\
\hline Mother: Graduate level degree & & & $\begin{array}{c}0.09 \\
(0.30)\end{array}$ & & & \\
\hline Mother $9-12 \mathrm{yr} *$ Treat & & & $\begin{array}{l}-0.45 \\
(0.42)\end{array}$ & & & \\
\hline Mother 13-16yr * Treat & & & $\begin{array}{l}-0.04 \\
(0.42)\end{array}$ & & & \\
\hline Mother BS/BA * Treat & & & $\begin{array}{l}-0.18 \\
(0.40)\end{array}$ & & & \\
\hline Mother Grad * Treat & & & $\begin{array}{c}0.19 \\
(0.41)\end{array}$ & & & \\
\hline Age*Treatment & $\begin{array}{c}0.03 \\
(0.03)\end{array}$ & & & & & \\
\hline Female*Treatment & & $\begin{array}{l}0.30^{*} \\
(0.17)\end{array}$ & & & & \\
\hline Children in $\mathrm{Hh}$. & & & & $\begin{array}{l}-0.02 \\
(0.07)\end{array}$ & & \\
\hline HH Size*Treatment & & & & $\begin{array}{l}-0.07 \\
(0.10)\end{array}$ & & \\
\hline Initial Share*Treatment & & & & & $\begin{array}{l}-0.02 \\
(0.04)\end{array}$ & \\
\hline $0,1,2$ Sharer & & & & & & $\begin{array}{c}-2.36^{* * *} \\
(0.15)\end{array}$ \\
\hline $8,9,10$ Sharer & & & & & & $\begin{array}{c}2.83 * * * \\
(0.26)\end{array}$ \\
\hline $0,1,2$ Sharer * Treat & & & & & & $\begin{array}{l}-0.09 \\
(0.20)\end{array}$ \\
\hline $8,9,10$ Sharer * Treat & & & & & & $\begin{array}{c}-0.83^{* *} \\
(0.38)\end{array}$ \\
\hline Constant & $\begin{array}{c}1.00 * * * \\
(0.21)\end{array}$ & $\begin{array}{c}0.95 * * * \\
(0.18)\end{array}$ & $\begin{array}{c}0.74 * * \\
(0.30)\end{array}$ & $\begin{array}{c}0.85^{* * * *} \\
(0.23)\end{array}$ & $\begin{array}{c}0.84 * * * \\
(0.19)\end{array}$ & $\begin{array}{c}3.38 * * * \\
(0.19)\end{array}$ \\
\hline $\begin{array}{l}\text { Observations } \\
\text { R-squared }\end{array}$ & $\begin{array}{c}2,331 \\
0.43\end{array}$ & $\begin{array}{c}2,331 \\
0.43\end{array}$ & $\begin{array}{c}2,148 \\
0.43\end{array}$ & $\begin{array}{c}2,184 \\
0.43\end{array}$ & $\begin{array}{c}2,331 \\
0.43\end{array}$ & $\begin{array}{c}2,331 \\
0.38\end{array}$ \\
\hline
\end{tabular}

Notes: Ordinary Least Squares (OLS) regression on sharing in the second dictator game. The outcome variables are shared 1 or not (Cols 1 and 3), shared 6 or not (Cols 2 and 4) or shared an equal amount in the second dicatator game. $* * * p<0.01, * * p<0.05, * p<0.1$ 
Table A6: Regression with Zero-Sharers Excluded

\begin{tabular}{|c|c|c|c|c|c|}
\hline & $\begin{array}{c}\text { (1) } \\
\text { Sharing }\end{array}$ & $\begin{array}{c}(2) \\
\text { Sharing }\end{array}$ & $\begin{array}{c}(3) \\
\text { Sharing }\end{array}$ & $\begin{array}{c}4) \\
\text { Sharing }\end{array}$ & $\begin{array}{c}\text { (5) } \\
\text { Sharing }\end{array}$ \\
\hline Share Treatment & $\begin{array}{c}0.46^{* * * *} \\
(0.09)\end{array}$ & $\begin{array}{c}0.42 * * * \\
(0.08)\end{array}$ & $\begin{array}{c}0.42 * * * \\
(0.09)\end{array}$ & $\begin{array}{c}0.42 * * * \\
(0.08)\end{array}$ & $\begin{array}{c}0.56^{* * * *} \\
(0.16)\end{array}$ \\
\hline Baseline sharing & $\begin{array}{c}0.67 * * * \\
(0.02)\end{array}$ & $\begin{array}{c}0.60 * * * \\
(0.02)\end{array}$ & $\begin{array}{c}0.60 * * * \\
(0.02)\end{array}$ & $\begin{array}{c}0.60 * * * \\
(0.02)\end{array}$ & $\begin{array}{c}0.60 * * * \\
(0.02)\end{array}$ \\
\hline Age & & $\begin{array}{c}0.16^{* * *} \\
(0.02)\end{array}$ & $\begin{array}{c}0.18 * * * \\
(0.02)\end{array}$ & $\begin{array}{c}0.16^{* * *} \\
(0.02)\end{array}$ & $\begin{array}{c}0.16^{* * * *} \\
(0.02)\end{array}$ \\
\hline Female & & $\begin{array}{l}-0.01 \\
(0.08)\end{array}$ & $\begin{array}{l}-0.03 \\
(0.09)\end{array}$ & $\begin{array}{l}-0.01 \\
(0.08)\end{array}$ & $\begin{array}{l}-0.01 \\
(0.08)\end{array}$ \\
\hline Children in Household & & & $\begin{array}{l}-0.04 \\
(0.05)\end{array}$ & & \\
\hline Mother: 9-12 years education & & & $\begin{array}{c}0.19 \\
(0.22)\end{array}$ & & \\
\hline Mother: $13-16$ years education & & & $\begin{array}{c}0.24 \\
(0.23)\end{array}$ & & \\
\hline Mother: Bachelor's Degree & & & $\begin{array}{c}0.09 \\
(0.22)\end{array}$ & & \\
\hline Mother: Graduate level degree & & & $\begin{array}{c}0.30 \\
(0.23)\end{array}$ & & \\
\hline Hofstede Score & & & & $\begin{array}{l}0.01 * * \\
(0.00)\end{array}$ & $\begin{array}{l}0.01 * * \\
(0.00)\end{array}$ \\
\hline Hofstede $\mathrm{x}$ Treat & & & & & $\begin{array}{l}-0.00 \\
(0.00)\end{array}$ \\
\hline Constant & $\begin{array}{c}1.65^{* * *} \\
(0.20)\end{array}$ & $\begin{array}{c}0.60 * * * \\
(0.23)\end{array}$ & $\begin{array}{c}0.39 \\
(0.34)\end{array}$ & $\begin{array}{c}0.22 \\
(0.22)\end{array}$ & $\begin{array}{c}0.15 \\
(0.23)\end{array}$ \\
\hline Country Dummy Variables & YES & YES & NO & NO & NO \\
\hline Observations & 2,331 & 2,331 & 2,119 & 2,331 & 2,331 \\
\hline R-squared & 0.40 & 0.43 & 0.43 & 0.43 & 0.43 \\
\hline
\end{tabular}

Notes: Ordinary Least Squares (OLS) regression on sharing in the second dictator game. The omitted category for education is "Less than 9 years". Standard errors in parentheses. Specifications (1)-(3) include country controls; specifications (4)-(5) do not.

$* * * p<0.01, * * p<0.05, * p<0.1$ 
Table A7: Regressions by Child Age

\begin{tabular}{lccc}
\hline & $(1)$ & $(2)$ & $(3)$ \\
& $\begin{array}{c}\text { Sharing } \\
\text { Age 6- }\end{array}$ & $\begin{array}{c}\text { Sharing } \\
\text { Age 6-10 }\end{array}$ & $\begin{array}{c}\text { Sharing } \\
\text { Age 10+ }\end{array}$ \\
\hline \multirow{3}{*}{ Share Treatment } & & & \\
& 0.31 & $0.43^{* * *}$ & $0.39^{* * *}$ \\
Baseline sharing & $(0.19)$ & $(0.11)$ & $(0.14)$ \\
& $0.55^{* * *}$ & $0.59^{* * *}$ & $0.60^{* * *}$ \\
Age & $(0.04)$ & $(0.03)$ & $(0.04)$ \\
& 0.01 & $0.31^{* * *}$ & $0.24^{* * *}$ \\
Female & $(0.11)$ & $(0.05)$ & $(0.08)$ \\
& 0.18 & -0.04 & $-0.26^{*}$ \\
Country Dummy Vars & $(0.19)$ & $(0.11)$ & $(0.14)$ \\
Constant & YES & YES & YES \\
& 0.81 & -0.66 & -1.46 \\
Observations & $(0.69)$ & $(0.47)$ & $(1.02)$ \\
R-squared & & & \\
& 710 & 1,009 & 612 \\
& 0.34 & 0.42 & 0.40 \\
\hline
\end{tabular}

Notes: Ordinary Least Squares (OLS) regression on sharing in the second dictator game. Standard errors in parentheses. All specifications include country controls.

$* * * p<0.01, * * p<0.05, * p<0.1$ 
Table A8: Summary Statistics by Country

\begin{tabular}{|c|c|c|c|c|c|c|}
\hline & Argentina & Canada & Chile & China & Colombia & Cuba \\
\hline Age & $\begin{array}{c}7.34 \\
(0.22)\end{array}$ & $\begin{array}{c}6.52 \\
(0.13)\end{array}$ & $\begin{array}{c}8.71 \\
(0.18)\end{array}$ & $\begin{array}{c}6.71 \\
(0.21)\end{array}$ & $\begin{array}{c}8.24 \\
(0.19)\end{array}$ & $\begin{array}{c}7.84 \\
(0.19)\end{array}$ \\
\hline Female & 0.56 & 0.52 & 0.59 & 0.49 & 0.46 & 0.62 \\
\hline Children in Household & $\begin{array}{c}2.11 \\
(0.07)\end{array}$ & $\begin{array}{c}2.03 \\
(0.04)\end{array}$ & $\begin{array}{c}2.25 \\
(0.09)\end{array}$ & $\begin{array}{c}1.44 \\
(0.05)\end{array}$ & $\begin{array}{c}1.94 \\
(0.07)\end{array}$ & $\begin{array}{c}1.94 \\
(0.06)\end{array}$ \\
\hline Mother: $0-8 y$ education & 0.02 & 0.01 & 0.06 & 0.16 & 0.03 & 0.00 \\
\hline Mother: $9-12 y$ education & 0.14 & 0.03 & 0.25 & 0.24 & 0.04 & 0.00 \\
\hline Mother: $13-16 y$ education & 0.26 & 0.10 & 0.35 & 0.06 & 0.16 & 0.04 \\
\hline Mother: BS/BA & 0.30 & 0.45 & 0.11 & 0.50 & 0.55 & 0.52 \\
\hline Mother: Grad level & 0.28 & 0.42 & 0.22 & 0.05 & 0.23 & 0.44 \\
\hline Baseline Sharing & $\begin{array}{c}3.33 \\
(0.19) \\
\end{array}$ & $\begin{array}{c}3.79 \\
(0.14) \\
\end{array}$ & $\begin{array}{c}4.40 \\
(0.13)\end{array}$ & $\begin{array}{c}4.34 \\
(0.18)\end{array}$ & $\begin{array}{c}3.26 \\
(0.16)\end{array}$ & $\begin{array}{c}4.53 \\
(0.14)\end{array}$ \\
\hline Number of children & 172 & 282 & 161 & 163 & 189 & 215 \\
\hline
\end{tabular}

\begin{tabular}{|c|c|c|c|c|c|c|}
\hline & Mexico & Norway & SA & Taiwan & Turkey & US \\
\hline Age & $\begin{array}{r}7.32 \\
(0.19)\end{array}$ & $\begin{array}{r}8.26 \\
(0.25)\end{array}$ & $\begin{array}{r}7.92 \\
(0.20)\end{array}$ & $\begin{array}{r}7.84 \\
(0.26)\end{array}$ & $\begin{array}{r}8.18 \\
(0.16)\end{array}$ & $\begin{array}{r}7.91 \\
(0.21)\end{array}$ \\
\hline Female & 0.48 & 0.49 & 0.53 & 0.52 & 0.50 & 0.53 \\
\hline Children in Household & $\begin{array}{r}2.08 \\
(0.05)\end{array}$ & $\begin{array}{r}2.42 \\
(0.07)\end{array}$ & $\begin{array}{r}2.67 \\
(0.08)\end{array}$ & $\begin{array}{r}1.95 \\
(0.05)\end{array}$ & $\begin{array}{r}1.96 \\
(0.04)\end{array}$ & $\begin{array}{r}2.51 \\
(0.08)\end{array}$ \\
\hline Mother: $0-8 y$ education & 0.03 & 0.00 & 0.06 & 0.04 & 0.23 & 0.01 \\
\hline Mother: 9-12y education & 0.17 & 0.12 & 0.66 & 0.13 & 0.35 & 0.08 \\
\hline Mother: 13-16y education & 0.50 & 0.01 & 0.24 & 0.29 & 0.15 & 0.20 \\
\hline Mother: BS/BA & 0.26 & 0.28 & 0.03 & 0.39 & 0.21 & 0.30 \\
\hline Mother: Grad level & 0.03 & 0.59 & 0.00 & 0.13 & 0.06 & 0.41 \\
\hline Baseline Sharing & $\begin{array}{r}3.57 \\
(0.14)\end{array}$ & $\begin{array}{r}3.81 \\
(0.20)\end{array}$ & $\begin{array}{r}2.76 \\
(0.17)\end{array}$ & $\begin{array}{r}4.46 \\
(0.28)\end{array}$ & $\begin{array}{r}3.59 \\
(0.14)\end{array}$ & $\begin{array}{r}4.93 \\
(0.19)\end{array}$ \\
\hline Number of children & 225 & 123 & 219 & 116 & 278 & 188 \\
\hline
\end{tabular}

Notes: This table provides summary statistics by country. Standard errors of means in parentheses. 
Table A9: Regression with Country Controls and Country $x$ Treatment Interactions

(1)

Sharing

Share Treatment

Point estimate

$-0.07 * * *$

$0.60 * * *$

Standard error

Baseline sharing

$0.17 * * *$

$-0.00$

Female

$-0.93 * * *$

$-1.17 * * *$

$-0.57 * * *$

$-0.42 * * *$

$-1.00 * * *$

$-0.64 * * *$

$-0.52 * * *$

$(0.01)$

$(0.02)$

$(0.03)$

$(0.08)$

Argentina

Chile

$-0.64 * * *$

$-0.43 * * *$

China

Colombia

Cuba

$-0.29 * * *$

$-0.58 * * *$

$0.43 * * *$

$0.67 * * *$

$0.69 * * *$

$1.28 * * *$

$1.11 * * *$

$0.75 * * *$

$(0.02)$

$(0.04)$

$(0.04)$

$(0.01)$

$(0.04)$

$(0.02)$

South Africa

$0.21 * * *$

$0.93 * * *$

$0.68 * * *$

$0.09 * * *$

$(0.04)$

$(0.01)$

$(0.01)$

$(0.02)$

$(0.01)$

Colombia x Treatment

Cuba x Treatment

$-0.50 * * *$

Mexico x Treatment

Norway x Treatment

SA $x$ Treatment

$0.97 * * *$

$(0.01)$

$(0.06)$

Turkey $\mathrm{x}$ Treatment

Constant

2,331

Observations

0.43

R-squared

Notes: Ordinary Least Squares (OLS) regression on sharing in the second dictator game. Standard errors in parentheses. All specifications include country controls. The US is the omitted country.

$* * * p<0.01, * * p<0.05, * p<0.1$ 
Table A10: Replication of Table 1 Excluding Age-Imbalanced Countries (Colombia and Turkey)

\begin{tabular}{|c|c|c|c|c|c|}
\hline & $\begin{array}{c}(1) \\
\text { Sharing }\end{array}$ & $\begin{array}{c}(2) \\
\text { Sharing }\end{array}$ & $\begin{array}{c}(3) \\
\text { Sharing }\end{array}$ & $\begin{array}{c}(4) \\
\text { Sharing }\end{array}$ & $\begin{array}{c}(5) \\
\text { Sharing }\end{array}$ \\
\hline Share Treatment & $\begin{array}{c}0.51^{* * * *} \\
(0.10)\end{array}$ & $\begin{array}{c}0.50 * * * \\
(0.10)\end{array}$ & $\begin{array}{c}0.53 * * * \\
(0.10)\end{array}$ & $\begin{array}{c}0.50 * * * \\
(0.10)\end{array}$ & $\begin{array}{c}0.64 * * * \\
(0.19)\end{array}$ \\
\hline Baseline sharing & $\begin{array}{c}0.67 * * * \\
(0.02)\end{array}$ & $\begin{array}{c}0.61 * * * \\
(0.02)\end{array}$ & $\begin{array}{c}0.61 * * * \\
(0.02)\end{array}$ & $\begin{array}{c}0.62 * * * \\
(0.02)\end{array}$ & $\begin{array}{c}0.62 * * * \\
(0.02)\end{array}$ \\
\hline Age & & $\begin{array}{c}0.15 * * * \\
(0.02)\end{array}$ & $\begin{array}{c}0.16^{* * * *} \\
(0.02)\end{array}$ & $\begin{array}{c}0.16^{* * * *} \\
(0.02)\end{array}$ & $\begin{array}{c}0.16^{* * *} \\
(0.02)\end{array}$ \\
\hline Female & & $\begin{array}{c}-0.04 \\
(0.10)\end{array}$ & $\begin{array}{l}-0.06 \\
(0.10)\end{array}$ & $\begin{array}{l}-0.05 \\
(0.10)\end{array}$ & $\begin{array}{l}-0.05 \\
(0.10)\end{array}$ \\
\hline Children in $\mathrm{Hh}$. & & & $\begin{array}{l}-0.07 \\
(0.06)\end{array}$ & & \\
\hline Mother: 9-12 years education & & & $\begin{array}{c}0.07 \\
(0.31)\end{array}$ & & \\
\hline Mother: $13-16$ years education & & & $\begin{array}{c}0.10 \\
(0.31)\end{array}$ & & \\
\hline Mother: Bachelor's Degree & & & $\begin{array}{c}0.10 \\
(0.31)\end{array}$ & & \\
\hline Mother: Graduate level degree & & & $\begin{array}{c}0.28 \\
(0.32)\end{array}$ & & \\
\hline Hofstede Score & & & & $\begin{array}{l}-0.00 \\
(0.00)\end{array}$ & $\begin{array}{l}-0.00 \\
(0.00)\end{array}$ \\
\hline Hofstede $\mathrm{x}$ Treat & & & & & $\begin{array}{l}-0.00 \\
(0.00)\end{array}$ \\
\hline Constant & $\begin{array}{c}1.64 * * * \\
(0.21)\end{array}$ & $\begin{array}{c}0.67 * * * \\
(0.25)\end{array}$ & $\begin{array}{c}0.52 \\
(0.41)\end{array}$ & $\begin{array}{c}0.56^{* * * *} \\
(0.18)\end{array}$ & $\begin{array}{l}0.48 * * \\
(0.20)\end{array}$ \\
\hline Country Dummy Variables & YES & YES & YES & NO & NO \\
\hline Observations & 1,864 & 1,864 & 1,697 & 1,864 & 1,864 \\
\hline R-squared & 0.40 & 0.42 & 0.42 & 0.41 & 0.41 \\
\hline
\end{tabular}

Note: This replicates Table 1 in the paper excluding Colombia and Turkey, since they were imbalanced This is an Ordinary Least Squares (OLS) regression on sharing in the second dictator game. The omitted category for education is "Less than 9 years". Standard errors in parentheses. Specifications (1)-(3) include country controls; specifications (4)-(5) do not. $* * * p<0.01, * * p<0.05, * p<0.1$ 